Louisiana State University

LSU Digital Commons

$11-1-2004$

\title{
High-threshold, Kv3-like potassium currents in magnocellular neurosecretory neurons and their role in spike repolarization
}

\author{
Talent Shevchenko \\ University of Tennessee Health Science Center \\ Ryoichi Teruyama \\ University of Tennessee Health Science Center \\ William E. Armstrong \\ University of Tennessee Health Science Center
}

Follow this and additional works at: https://digitalcommons.Isu.edu/biosci_pubs

\section{Recommended Citation}

Shevchenko, T., Teruyama, R., \& Armstrong, W. (2004). High-threshold, Kv3-like potassium currents in magnocellular neurosecretory neurons and their role in spike repolarization. Journal of Neurophysiology, 92 (5), 3043-3055. https://doi.org/10.1152/jn.00431.2004

This Article is brought to you for free and open access by the Department of Biological Sciences at LSU Digital Commons. It has been accepted for inclusion in Faculty Publications by an authorized administrator of LSU Digital Commons. For more information, please contact ir@lsu.edu. 


\title{
High-Threshold, Kv3-Like Potassium Currents in Magnocellular Neurosecretory Neurons and Their Role in Spike Repolarization
}

\author{
Talent Shevchenko, Ryoichi Teruyama, and William E. Armstrong \\ Department of Anatomy and Neurobiology, University of Tennessee Medical School, Memphis, Tennessee 38163
}

Submitted 27 April 2004; accepted in final form 2 July 2004

\begin{abstract}
Shevchenko, Talent, Ryoichi Teruyama, and William E. Armstrong. High-threshold, Kv3-like potassium currents in magnocellular neurosecretory neurons and their role in spike repolarization. $J \mathrm{Neu}$ rophysiol 92: 3043-3055, 2004. First published July 7, 2004; 10.1152/ jn.00431.2004. We identified Kv3-like high-threshold $\mathrm{K}^{+}$currents in hypothalamic supraoptic neurons using whole cell recordings in hypothalamic slices and in acutely dissociated neurons. Tetraethylammonium (TEA)-sensitive currents $(<1 \mathrm{mM}$ TEA) evoked from $-50 \mathrm{mV}$ were characterized by a large component that inactivated in $10-30 \mathrm{~ms}$, and a smaller, persistent component that inactivated in 1-2 s. $I / V$ relations in dissociated neurons revealed TEA-subtracted currents with a slope and voltage dependency consistent with the presence of Kv3-like channels. In slices, tests with 0.01-0.7 mM TEA produced an $\mathrm{IC}_{50}$ of 200-300 $\mathrm{nM}$ for both fast and persistent currents. The fast transient current was similar to currents associated with the expression of Kv3.4 subunits, given that it was sensitive to BDS-I $(100 \mathrm{nM})$. The persistent TEA-sensitive current appeared similar to those attributed to Kv3.1/3.2 subunits. Although qualitatively similar, oxytocin (OT) and vasopressin (VP) neurons in slices differed in the stronger presence of persistent current in VP neurons. In both cell types, the $\mathrm{IC}_{50}$ for TEA-induced spike broadening was similar to that observed for current suppression in voltage clamp. However, TEA had a greater effect on the spike width of VP neurons than of OT neurons. Immunochemical studies revealed a stronger expression of the Kv3.1b $\alpha$-subunit in VP neurons, which may be related to the greater importance of this current type in VP spike repolarization. Because OT and VP neurons are not considered fast firing, but do exhibit frequency- and calcium-dependent spike broadening, Kv3-like currents may be important for maintaining spike width and calcium influx within acceptable limits during repetitive firing.
\end{abstract}

\section{IN T R O D U C T I O N}

Magnocellular neurosecretory cells (MNCs) of the supraoptic (SON) and paraventricular nuclei (PVN) in the mammalian hypothalamus synthesize the neuropeptides oxytocin (OT) or vasopressin (VP) and transport these hormones to axonal endings at the neurohemal contact zone in the neurohypophysis. The terminal release of OT and VP is a function of the rate and pattern of action potentials (APs) generated somatodendritically (Bicknell 1988; Poulain and Wakerley 1982). Many of the membrane properties, known to shape these APs, their afterpotentials, and the resulting firing patterns in these neurons, have been described. Among these are $\mathrm{K}^{+}$currents generated by voltage- and/or $\mathrm{Ca}^{2+}$-activated $\mathrm{K}^{+}$channels. For example, SON neurons have a prominent $I_{\mathrm{A}}$ (Bourque 1988; Fisher et al. 1998; Hlubek and Cobbett 1997), an SK-mediated $I_{\mathrm{AHP}}$ (Kirkpatrick and Bourque 1996), BK-mediated $I_{\mathrm{C}}$

Address for reprint requests and other correspondence: W. E. Armstrong, Department of Anatomy and Neurobiology, University of Tennessee Medical School, 855 Monroe Avenue, Memphis, TN 38163 (E-mail: warmstrong@utmem.edu).

www.jn.org
(Dopico et al. 1999; Roper et al. 2003; Stern and Armstrong 1997), and delayed rectifier-type currents (Cobbett et al. 1989; Hlubek and Cobbett 1997) that contribute to spike repolarization and spike afterhyperpolarizations. Similar currents have been found in PVN neurons (Li and Ferguson 1996; Luther et al. 2000; Nagatomo et al. 1995). However, to date, there has been little dissection of delayed rectifiers in MNCs.

In the large family of voltage-gated $\mathrm{K}^{+}(\mathrm{Kv})$ channels, the Kv3 subfamily includes genes of four $\alpha$-subunits: Kv3.1$\mathrm{Kv} 3.4$, all of which evoke high-voltage-activated outward $\mathrm{K}^{+}$ currents. The specific assembly of these various subunits is pivotal for shaping AP repolarization, the AP afterhyperpolarization, and consequently the firing pattern exhibited by a given neuron type (Rudy et al. 1999). Slowly inactivating currents ascribed to Kv3.1/3.2 subunits (which typically coassemble) allow rapid repolarization and high-frequency firing, and have been identified in the globus pallidus (Baranauskas et al. 1999; Hernández-Pineda et al. 1999), fast-spiking neocortical neurons (Chow et al. 1999), hippocampal interneurons (Martina et al. 1998; Riazanski et al. 2001), and brain stem auditory neurons (Wang et al. 1998). The Kv3.4 subtype exhibits voltage dependency similar to that of the Kv3.1/3.2 subtype, but is rapidly inactivating, and participates in AP repolarization in some cell types (Baranauskas et al. 2003; Riazanski et al. 2001). Intermediate inactivation rates $(<1 \mathrm{~s})$ have been identified for Kv3.3 subtypes (Coetzee et al. 1999). Kv3 subunits can form hetero-oligomeric channels of intermediate, or unusual properties (Baranauskas et al. 2003; MacKinnon 1991; Weiser et al. 1994) and are regulated by phosphorylation (Beck et al. 1998) and site-specific proteolysis (Hoshi et al. 1990). All members of the Kv3 subtype exhibit a similar sensitivity to low $(<1 \mathrm{mM})$ concentrations of tetraethylammonium (TEA), but some may be distinguished by differential sensitivity to other toxins, such as 4-aminopyridine (4-AP) and BDS-I (Coetzee et al. 1999; Diochot et al. 1998). An investigation of Kv3.1, 3.2, and 3.4 mRNAs indicated only scattered cells in the preoptic area $(\mathrm{Kv} 3.1,3.2)$ and anterior hypothalamus (Kv3.4), with no mention of the SON or PVN (Weiser et al. 1994).

In this study we characterized high voltage-gated $\mathrm{K}^{+}$currents in identified OT and VP neurons from the SON in hypothalamic slices using voltage-clamp recordings and pharmacologic sensitivity. For clarity, we will refer to these as Kv3-like currents where appropriate. We also examined the characteristics of these currents in acutely dissociated cells, to more accurately assess their voltage dependency, and inacti3043

\footnotetext{
The costs of publication of this article were defrayed in part by the payment of page charges. The article must therefore be hereby marked "advertisement" in accordance with 18 U.S.C. Section 1734 solely to indicate this fact.
} 
vation. The role of these currents in spike repolarization was then assessed in current-clamp recordings. Finally, we used immunohistochemistry to investigate whether Kv3 subtypes could be localized to the SON. Parts of this study were previously presented in abstract form (Armstrong and Teruyama 2001; Shevchenko and Armstrong 2001).

\section{METHODS}

\section{Slices versus dissociated cells}

Although problematic for precise evaluation of current kinetics and voltage dependency ascribed to the presence of dendrites, the slice preparation afforded us the opportunity to reliably record $\mathrm{K}^{+}$currents in viable adult SON neurons, and further to compare some of their properties in OT and VP neurons using established, double-labeling immunochemical procedures. Whereas single-cell polymerase chain reaction (PCR) techniques have been applied to SON neurons (Xi et al. 1999) and could be useful to identify acutely dissociated cells, there is significant co-localization of OT and VP mRNA. Although SON neurons in slices would have some dendritic tree, the influence of poor space clamp on the time course and activation voltage dependency is not severe for depolarization-activated $\mathrm{K}^{+}$currents (Surmeier et al. 1994). Another factor to consider is the relatively large currents recorded in slices, compounding series resistance errors. As a compromise to these advantages and disadvantages, we have verified the basic characteristics of Kv3-like currents studied in slices using a sample of unidentified, acutely dissociated SON neurons.

\section{Hypothalamic slices}

The methods are essentially those of Stern et al. (1999, 2000). Female virgin rats (150-200 g; random cycling) were anesthetized with sodium pentobarbital $(50 \mathrm{mg} / \mathrm{kg}$, intraperitoneally [ip]) and perfused through the heart with cold artificial cerebrospinal fluid (ACSF) in which $\mathrm{NaCl}$ was replaced by an equiosmolar amount of sucrose (see following text). The brain was rapidly removed after decapitation, blocked, and coronal slices were cut on a vibrating microtome (Campden Instruments). Slices were placed in ACSF consisting of (in $\mathrm{mM}$ ) $125 \mathrm{NaCl}, 26 \mathrm{NaHCO}_{3}, 2.5 \mathrm{KCl}, 1.25$ $\mathrm{NaH}_{2} \mathrm{PO}_{4}, 20$ glucose, $2 \mathrm{CaCl}_{2}, 1 \mathrm{MgSO}_{2}, 0.4$ ascorbic acid at $\mathrm{pH}$ $7.3-7.4$, with an osmolality of $300-310 \mathrm{mOsm} / \mathrm{kg} \mathrm{H} \mathrm{H}_{2} \mathrm{O}$, and saturated with $95 \% \mathrm{O}_{2}-5 \% \mathrm{CO}_{2}$. Slices were incubated in this solution $\leq 8 \mathrm{~h}$ at room temperature after a 1.5 -h preincubation at $32^{\circ} \mathrm{C}$. $\mathrm{A} \mathrm{Ca}^{2+}$-free modification of ACSF had $\mathrm{Ca}^{2+}$ replaced by $3 \mathrm{mM}$ EGTA-NaOH and $2 \mathrm{mM} \mathrm{MgCl}_{2}$. Decreasing $\mathrm{NaCl}$ compensated for the excess of $\mathrm{Na}^{+}$ ions added with $\mathrm{NaOH}$.

\section{Dissociated cells}

Dissociated cells were prepared as reported by Hlubek and Cobbett (1997). For enzymatic dissociation brain slices were preincubated in ACSF containing $0.1 \mathrm{mg} / \mathrm{ml}$ pronase for $75 \mathrm{~min}$ at $32^{\circ} \mathrm{C}$. The SON area was triturated with a fire-polishing Pasteur pipette of about $0.2-0.5 \mathrm{~mm}$ inner diameter. The cell suspension was adhered to a cover glass that was then placed in the same chamber used for patch-clamp recording from slices. Cells adhered within a few minutes, after which recordings could be made under visual guidance. Recordings from dissociated MNCs in this region were based on cell diameters $(>25 \mu \mathrm{m})$, as determined by Oliet and Bourque (1992).

\section{Electrophysiology}

Electrophysiological recordings used the whole cell configuration of the patch-clamp technique (Hamill et al. 1981). Data were obtained with an Axopatch 200B (Axon Instruments, Foster City, CA) patch- clamp amplifier. Pipettes were made with borosilicate glass capillary tubes (150T-3, Warner Instrument) and filled with an intracellular solution containing (in $\mathrm{mM}$ ) $142.6 \mathrm{~K}^{+}$gluconate, $7.4 \mathrm{KCl}, 0.9 \mathrm{MgCl}_{2}$, 10 HEPES, 0.2 EGTA, 4 ATP-Mg, and 0.3 GTP-Na, biocytin 1-2 $\mathrm{mg} / \mathrm{ml}$; pH 7.2-7.3 with $\mathrm{KOH}$, osmolality $280-300 \mathrm{mOsm} / \mathrm{kg}$. In some experiments, $2 \mathrm{mM}$ BAPTA was used instead of $0.2 \mathrm{mM}$ EGTA. For dissociated cells, biocytin was omitted from the patch solution because we were not able to successfully retain cells for immunohistochemical identification. The standard ACSF solution described above was used as the initial external solution for both dissociated cell and slice recordings. For voltage-clamp experiments, $0.5 \mu \mathrm{M}$ tetrodotoxin (TTX) was applied to block sodium currents. All the pharmacological agents were applied as additives in external solution. BDS-I was dissolved in the presence of $0.03-0.1 \mathrm{mg} / \mathrm{ml}$ bovine serum albumin. All recordings, including those from dissociated neurons, were done at $33 \pm 0.5^{\circ} \mathrm{C}$.

The initial electrode resistance was 6-9 $\mathrm{M} \Omega$. Voltages were corrected for a liquid junction potential of $-10 \mathrm{mV}$, measured empirically according to Neher (1992). The acquisition rate was $20 \mathrm{kHz}$ with filtering at $2-5 \mathrm{kHz}$. The ground electrode consisted of a silver/silver chloride wire coupled to an Agar (4\%) bridge saturated with $3 \mathrm{M} \mathrm{KCl}$.

In voltage clamp, whole cell capacitance and series resistance were compensated (75-80\%) and monitored after each recorded series. The recordings reported herein all had a series resistance $<20 \mathrm{M} \Omega$ before compensation, and were terminated if exceeding this value.

Current-clamp recordings were performed in the fast mode of the 200B amplifier. Voltage signals were digitized at $20 \mathrm{kHz}$. After each experiment, changes in the electrode tip potential were estimated by measuring the DC offset of the electrode in the bathing medium and considered acceptable if the offset was $\pm 5 \mathrm{mV}$.

Dendrotoxin (DTX), TTX, and BDS-I were purchased from Alomone Labs. Additional BDS-I was a gift from Drs. Michel Lazdunski and Sylvie Diochot. All other chemicals for media preparation were purchased from Fisher, Sigma, or J. T. Baker Chemical companies.

\section{Data analysis}

To obtain activation parameters for $\mathrm{Kv}$-like currents in dissociated neurons, we plotted the current and normalized conductance $\left(\mathrm{G} / \mathrm{G}_{\max }\right)$ against voltage using TEA-subtracted currents. Current amplitude for the fast transient component was evaluated at its peak and for the persistent current was averaged over the last $50-100 \mathrm{~ms}$ of a $2 \mathrm{~s}$ depolarization pulse. The conductance $(\mathrm{G})$ was calculated as $\mathrm{G}=$ $\mathrm{I} /\left(V-V_{\text {rev }}\right)$. The $\mathrm{K}^{+}$current reversal potential $\left(V_{\text {rev }}\right)$ was estimated at $-90 \mathrm{mV}$ from a series of tail currents steps to -50 to $-120 \mathrm{mV}$ after a $20 \mathrm{~ms}$ depolarization step from -50 to $+20 \mathrm{mV}$. Conductance data were fitted to a Boltzmann function

$$
\mathrm{G} / \mathrm{G}_{\max }=1 /\left[1+\exp \left(V_{\mathrm{m}}-V_{1 / 2}\right) / \mathrm{k}\right]
$$

to calculate the activation threshold, half-activation value $\left(V_{1 / 2}\right)$, and the slope factor $(\mathrm{k}) . V_{\mathrm{m}}$ is the membrane potential.

Exponential fitting of the currents $(+50 \mathrm{mV}$ depolarization pulse, 2 $\mathrm{s}$ duration) provided inactivation time constants $(\tau)$ for the transient (the fastest inactivation value) and the persistent (the slowest inactivation value) components. Curve fits were made from averages of 3-6 records. Although in several neurons an intermediate $\tau$ was present, it was an inconsistent property across all neurons. For these neurons, the fastest and slowest values of $\tau$ were reported from the fits using 3 exponentials.

Current-clamp records of spikes were aligned at the rising phase and averaged $(n>3)$ to measure spike width. Spike widths were measured at threshold (base width) and at 1/2 spike amplitude (1/2 width). Rise times were calculated from the $10-90 \%$ region of spike amplitude. DC current injection was used to maintain a slow $(<1 \mathrm{~Hz})$, irregular pattern of activity near threshold. 

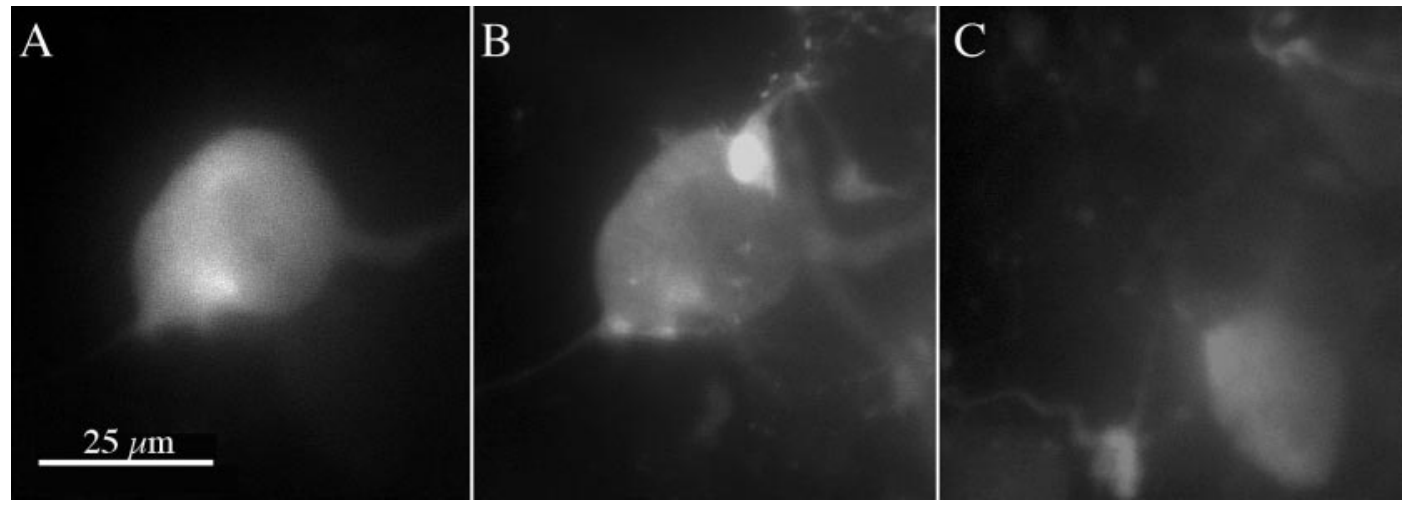

FIG. 1. Immunoidentification of a vasopressin (VP) neuron in the slice. A: biocytin-labeled neuron. $B$ : positive immunoreaction to VP-Ab; $C$ : negative immunoreaction to oxytocin (OT)-Ab. See METHODs for details.

All values are shown as means \pm SD. Data analysis was performed with Clampex (8.0 or 8.2), AxoGraph 4.6 (Axon Instruments), Igor Pro 4.0 (Wavemetrics), and Excel 8.0 (Microsoft) software. Withingroup statistical comparisons were analyzed with the nonparametric Wilcoxon's signed-rank test for paired samples, or for multiple comparisons, Friedman's test. Between-group comparisons of OT and VP neurons were made with the nonparametric Mann-Whitney $U$ test. Only significant $P$ values $(<0.05)$ are listed. All tests were performed using Statview 5.0 software.

\section{Immunohistochemistry}

To identify the cell type after the recording session, slices were fixed 1-7 days in $0.15 \mathrm{M}$ sodium phosphate-buffered $4 \%$ paraformaldehyde, and $0.2 \%$ picric acid ( $\mathrm{pH} 7.2-7.4)$, rinsed in phosphatebuffered saline (PBS) containing 0.5\% Triton-X 100, and incubated overnight at $4^{\circ} \mathrm{C}$ in avidin conjugated to alphamethylcoumarin (AMCA; Vector Labs). Avidin-AMCA was diluted 1:1,000 in PBS containing 0.5\% Triton-X 100. After rinsing 3 times in PBS the biocytin-labeled cells were identified with UV illumination (DM-400 Nikon filter) on a Nikon Optiphot microscope.

Immunoidentification of recorded neurons was performed with previously published procedures (Stern et al. 1999; Teruyama and Armstrong 2002). Briefly VP neurons were identified with a rabbit antiserum specific for VP-neurophysin (provided by Alan Robinson, UCLA Medical School) at a 1:20,000 dilution, and then revealed by a fluorescein-conjugated goat anti-rabbit secondary antibody (1:200). OT neurons were labeled with a mouse antibody PS 36 (provided by Harold Gainer, National Institutes of Health) specific for OT-neurophysin, at a dilution of 1:1,000, and then revealed by a Texas Red-conjugated goat anti-mouse secondary antibody (1:200; Vector or Sigma Chemicals). All antibodies were diluted with PBS containing $0.5 \%$ Triton X-100. Incubation times for primary and secondary antibody cocktails were $16-24 \mathrm{~h}$ at $4^{\circ} \mathrm{C}$. Figure 1 illustrates an immunolabeled neuron using this protocol.
A

$\mathrm{V}_{\text {hold }}-100 \mathrm{mV}$

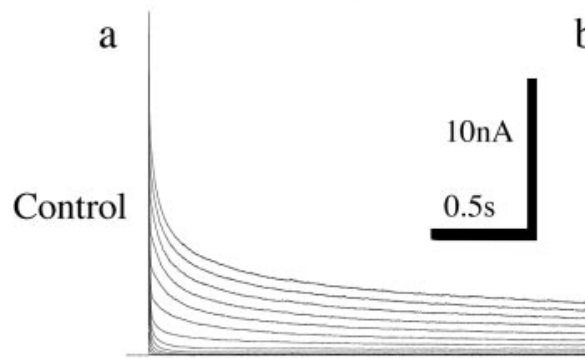

$\mathrm{V}_{\text {hold }}-50 \mathrm{mV}$

b
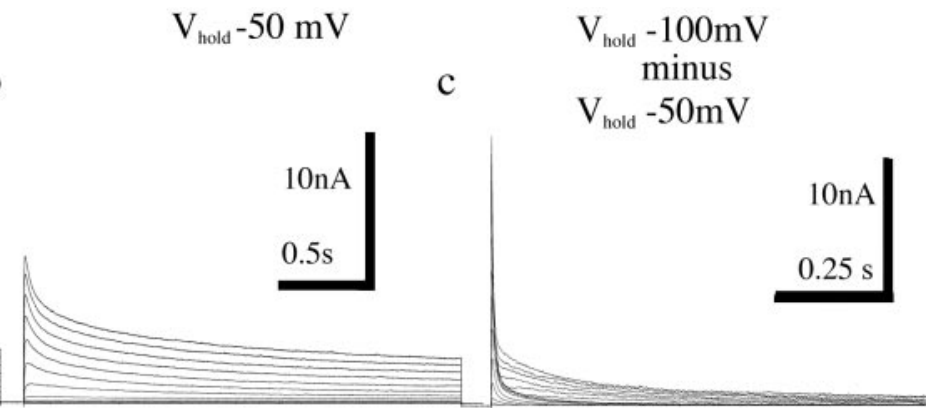

B

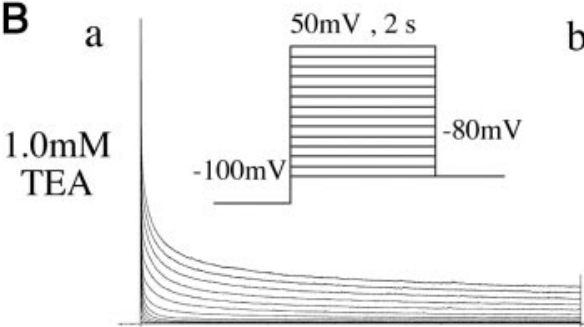

b

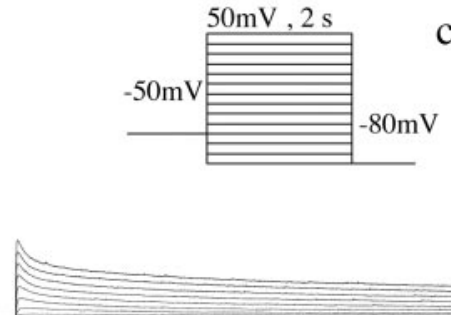

$\mathrm{c}$

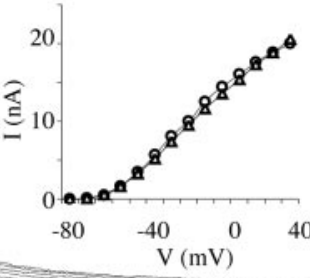

FIG. 2. Tetraethylammonium (TEA, $1.0 \mathrm{mM}$ )-blocked current does not contain fast $I_{\mathrm{A}}$ (Kv4-like) current activated from Vhold $=-100 \mathrm{mV}$. $A$ : control currents evoked in a MNC from: $A a$, Vhold $=-100 \mathrm{mV}$ and $A b$, Vhold $=-50 \mathrm{mV}$. Ac: current evoked at $-50 \mathrm{mV}$ in $A b$ is subtracted from the current evoked at $-100 \mathrm{mV}$ in $A a$ to isolate the lower threshold, $I_{\mathrm{A}}$-like current. $B$ : currents evoked with the same protocols as in $A$, in the presence $1.0 \mathrm{mM}$ TEA. $B a$ : Vhold $=-100 \mathrm{mV}$. $B b$ : Vhold $=-50 \mathrm{mV}$. $B c$ : current evoked at $-50 \mathrm{mV}$ is subtracted from that recorded at $-100 \mathrm{mV}$. Subtracted, $I_{\mathrm{A}}$-like current in $B c$ is only slightly affected by $1 \mathrm{mM}$ TEA, whereas the high-voltage activated $\mathrm{K}^{+}$current at $-50 \mathrm{mV}(B b)$ is strongly suppressed. Current family evoked with this protocol appears to consist of a large rapidly inactivating, and a smaller more slowly inactivating component (Fisher et al. 1998), the latter of which is still an order of magnitude faster than the slower, high-voltage component studied herein. (Inset in $B c$ shows the current/voltage plot for the control $I_{\mathrm{A}}$ current in $A c(\bigcirc)$ and TEA-treated $(\triangle)$ current in Bc. Insets in $B a$ and $B b$ show voltage protocols used to evoke the currents. 
Rabbit polyclonal antibodies to Kv3 peptide subunits (Kv3.1b, $\mathrm{Kv3}$.2, Kv3.3, and Kv3.4) were purchased from Alomone Labs. Random cycling female rats $(n=15)$ were placed under deep anesthesia with sodium pentobarbital $(50 \mathrm{mg} / \mathrm{kg}$, ip). The animals were perfused transcardially with PBS for exsanguination, followed by the same fixative used for slices described above. The brains were further fixed overnight at $4^{\circ} \mathrm{C}$. Some brains were sectioned on a vibrating microtome (Lancer) at $75 \mu \mathrm{m}$, others on a freezing microtome at $40 \mu \mathrm{m}$. In the latter case, brains were first cryoprotected in fixative to which $30 \%$ sucrose was added. After rinsing off fixative with PBS, the sections were pretreated $1-2 \mathrm{~h}$ with a solution of $2 \%$ normal goat serum and $0.3 \% \mathrm{H}_{2} \mathrm{O}_{2}$ in PBS. Primary antibodies were dissolved in PBS and $0.5 \%$ Triton-X and tested at dilutions ranging from 1:200 to 1:5,000, with incubations of $48 \mathrm{~h}$. Sections were then processed with biotinylated goat-anti-rabbit (GAR-B; Vector) at 1:200 overnight, rinsed, then incubated with avidin-biotin-peroxidase complex (ABC; Vector Labs) for $1-4 \mathrm{~h}$, rinsed and reacted with diaminobenzidine (DAB; $60 \mathrm{mg} / \mathrm{ml}$ ) and $0.003 \% \mathrm{H}_{2} \mathrm{O}_{2}$ for about 10 min. Sections reacted for DAB were mounted onto gelatin-coated slides, dried, and coverslipped with Permount. Antibodies giving positive results were further tested for specificity using the subunit peptide provided by Alomone for absorption $(1 \mu \mathrm{g} / \mu \mathrm{g}$ antibody protein). The micrographs in Fig. 11 were generated from 10 focal plane images, each $2 \mu \mathrm{m}$ apart along the z-axis, which were then averaged (IP Labs Software). A synthetic projection of the averaged image stack (which removes out-of-focus information) was produced using a deblurring algorithm published by Agard et al. (1989).

Additional sections were double labeled using mouse monoclonal antibodies to OT (PS 36) or VP-associated neurophysins (PS 41), provided by Harold Gainer, National Institutes of Health. These antibodies were diluted 1:500-1:1,000, and either one of them was mixed in a cocktail with the Kv3.1b antibody $(1: 1,000)$. Primary antibodies were rinsed and followed by a cocktail of secondary antibodies using goat-anti-mouse- (GAM) Texas Red and GARfluorescein (FITC). All antibodies were diluted with PBS containing $0.5 \%$ Triton $\mathrm{X}-100$, and incubation times for primary and secondary antibody cocktails were $24-48 \mathrm{~h}$ at $4^{\circ} \mathrm{C}$. Sections were rinsed in PBS and mounted on glass slides with 50:50 glycerol:PBS. Coverslips were sealed at the edge with nail polish. Tissue sections were examined with a $60 \times$ oil immersion objective with a confocal microscope (Biorad 1024) equipped with a krypton-argon laser. FITC was examined with a 488-nm excitation filter (emission band-pass 522 $\mathrm{nm})$ and Texas Red was examined with a 568-nm excitation filter (emission band-pass $605 \mathrm{~nm}$ ). The optical section thickness was 1 $\mu \mathrm{m}$.

\section{RES U L T S}

\section{Voltage clamp}

SUPRAOPTIC NEURONS POSSESS A KV3-LIKE TRANSIENT AND PERSISTENT OUTWARD $\mathrm{K}^{+}$CURRENT. Because MNCs are known to possess $\mathrm{Ca}^{2+}$-dependent $\mathrm{K}^{+}$currents (Cobbett et al. 1989: Li and Ferguson 1996), including SK (Kirkpatrick and Bourque 1996) and BK varieties (Dopico et al. 1999), we tested for Kv3-type currents with reduced $\mathrm{Ca}^{2+}$ (lowering $\left[\mathrm{Ca}^{2+}\right]_{\mathrm{O}}$ to 0 , and adding $3 \mathrm{mM}$ EGTA) in the ACSF. Under these conditions, MNCs exhibited a fast-activating, transient outward current, and a more slowly inactivating outward current when depolarized from -100 to $+50 \mathrm{mV}$ (Fig. 2). Previous studies have characterized a large $I_{\mathrm{A}}$-type (low threshold and inactivating) $\mathrm{K}^{+}$current in MNCs (Bourque 1988; Fisher et al. 1998; Hlubek and Cobbett 1997; Li and Ferguson 1996; Nagatomo et al. 1995). To remove the influence of $I_{\mathrm{A}}$, we subtracted records taken at holding potentials of $-50 \mathrm{mV}$ from those taken at
$-100 \mathrm{mV}$. As expected, the $I_{\mathrm{A}}$-type current was effectively inactivated at $-50 \mathrm{mV}$, and was insensitive to $1 \mathrm{mM}$ TEA. Thus we used a holding potential of $-50 \mathrm{mV}$, and by subtraction studied only the TEA-sensitive portion of the current, as shown in Fig. 3. TEA-subtracted currents were activated with a threshold of -20 to $-10 \mathrm{mV}$, and all neurons contained a fast transient $\left(\tau_{\text {finact }}=10-30 \mathrm{~ms}\right.$ ) and a more slowly inactivating $\left(\tau_{\text {sinact }}=1-2 \mathrm{~s}\right)$ component.

We tested the effects of low doses of TEA $(<1 \mathrm{mM})$, a hallmark of Kv3-type channels (Coetzee et al. 1999), on currents evoked with a step from -50 to $+50 \mathrm{mV}$ in both VP and OT neurons. A Hill function was fit to all points in the dose-response curve $(n=6-11$ for each dose). No cell was tested with more than 4 doses of TEA, but typically only 2 doses were tested on a particular cell. Figure 4 shows that the fast and slow components of the outward current were attenuated by TEA with a similar sensitivity, and this was true of both OT and VP neurons. In both cell types, the inhibition of the transient (peak) current was well fit by the Hill function up to a dose of $1 \mathrm{mM}$ TEA. The $1 / 2$ maximal value for the single fits were $0.29 \pm 0.05 \mathrm{mM}$ for OT neurons, and $0.21 \pm 0.07$

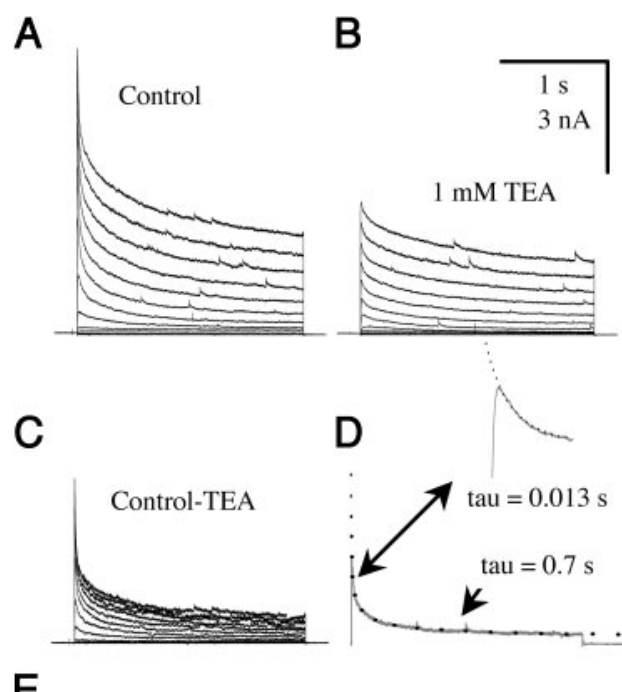

E

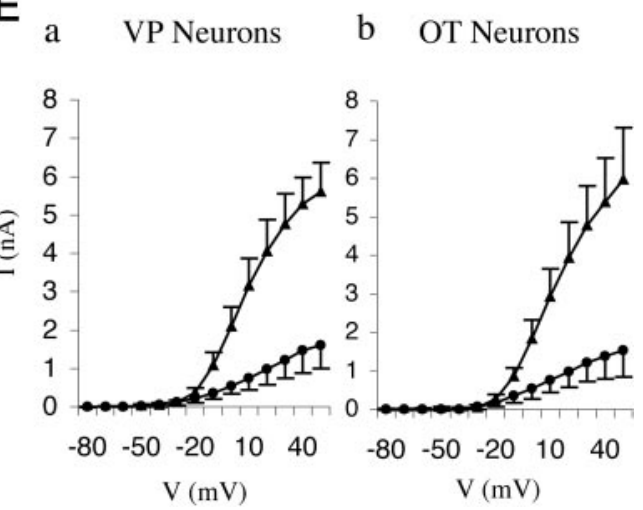

FIG. 3. A high-threshold, Kv3-like current sensitive to $1 \mathrm{mM}$ TEA. A: control current evoked while holding at $-50 \mathrm{mV}$, with $10-\mathrm{mV}$ steps from -100 to $+50 \mathrm{mV}$ (see protocol in Fig. $1 B b$ ). $B: 1.0 \mathrm{mM}$ TEA suppresses the current. $C$ : TEA-sensitive current is derived by subtracting the traces in $B$ from those in $A$. $D$ : exponential fitting of a Kv3-like current evoked at $0 \mathrm{mV}$. Note the fast (double arrow, inset) and slower decaying portions of the current (arrow). Inactivation time constants are given for this fit. $E$ : current amplitudes of TEA-sensitive component plotted against voltage ( $\bullet$, transient component; $\Delta$, persistent component) for VP neurons $(a ; n=7)$ and OT neurons $(b ; n=$ $9)$. 


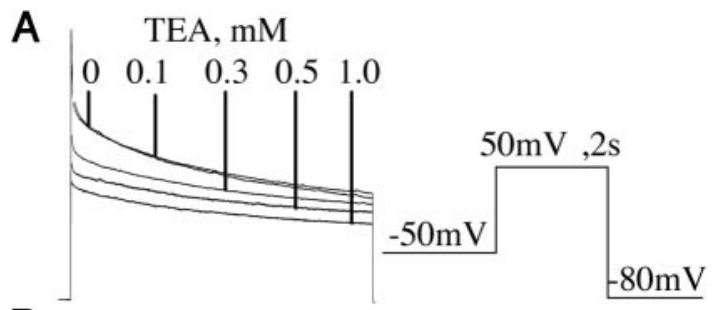

B

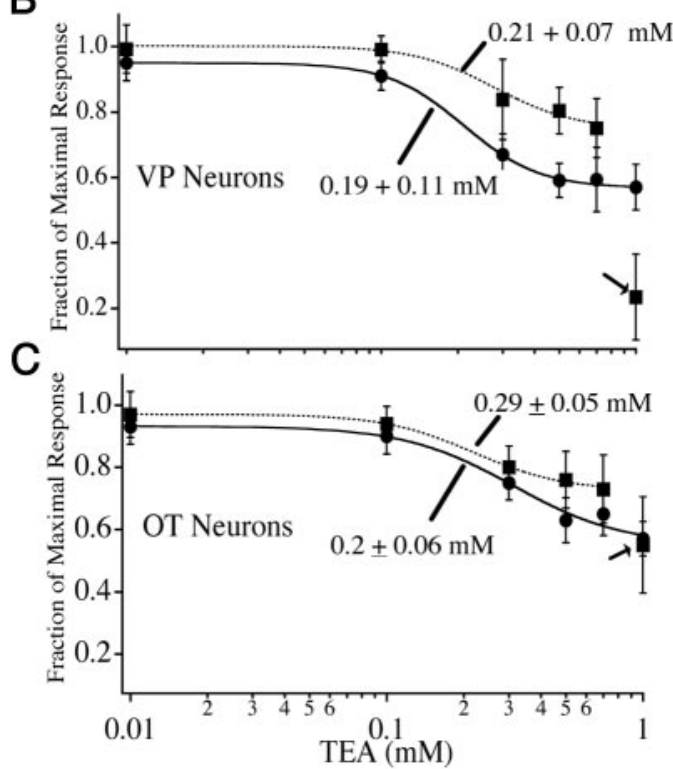

FIG. 4. TEA dose-response inhibition of high-threshold $\mathrm{K}^{+}$currents in magnocellular neurosecretory cells (MNCs). A: current evoked in a MNC at TEA concentrations $0.05-1.0 \mathrm{mM}$. Inset: voltage protocol used to evoke the currents. $B$ and $C$ : current amplitude against TEA fitted with Hill function for VP $(B)$ and OT neurons $(C)$. Solid lines indicate the fit for peak of the transient component, dashed lines the fit for the persistent component. Arrows show the persistent component values at $1.0 \mathrm{mM}$ TEA that were not included because they strongly reduced the goodness of fit.

$\mathrm{mM}$ for VP neurons. For the persistent current, the doseresponse curve was well fit only to doses $\leq 0.7 \mathrm{mM}$ TEA (Fig. 4). The $1 / 2$ maximal values for the inhibition of this component were similar between the 2 cell types: $0.2 \pm 0.06$ and $0.19 \pm$ $0.11 \mathrm{mM}$, for OT and VP neurons, respectively. Whereas VP and OT neurons were similarly sensitive to doses of TEA $<1$ $\mathrm{mM}$, the difference in the proportion of the slower current inhibited at $1 \mathrm{mM}$ was much greater for VP than for OT neurons $(P<0.0025)$. Thus about $75 \%$ of the slow current in VP neurons was blocked at this dose.

The TEA-sensitive current rapidly activated (peaking $<5$ ms) and inactivated with 2-3 time constants, although the presence of an intermediate component was inconsistent. The transient current inactivated in $10-30 \mathrm{~ms}$, corresponding well

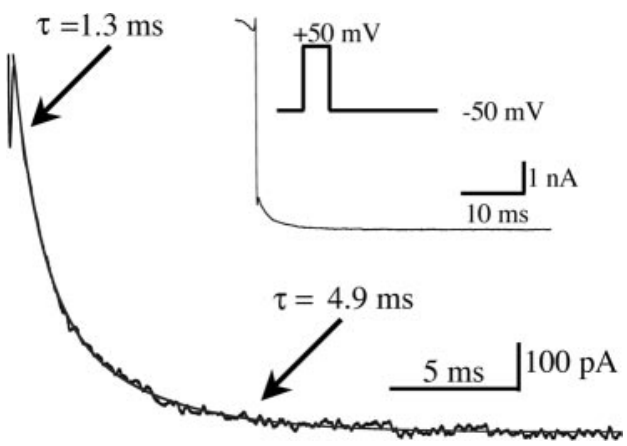

FIG. 5. TEA-sensitive tail currents in an OT neuron are characterized by fast decays. Outward current was evoked by a step from -50 to $+50 \mathrm{mV}$ for $20 \mathrm{~ms}$ in the presence and absence of $0.7 \mathrm{mM}$ TEA, and the TEA-subtracted current is shown. Subsequent step back to $-50 \mathrm{mV}$ was associated with a rapidly decaying tail current fit with 2 time constants. Inset: trace at lower resolution includes the end of the response to the $20 \mathrm{~ms},+50 \mathrm{mV}$ step.

to Kv3.4-type currents in expression systems (Coetzee et al. 1999; Rudy et al. 1999). To compare OT and VP neurons, we examined the fastest $\left(\tau_{\text {finact }}\right)$ and slowest $\left(\tau_{\text {sinact }}\right)$ time constants of inactivation from TEA-subtracted currents evoked at a single step, from -50 to $+50 \mathrm{mV}$. Within each cell type, we also compared currents sensitive to 0.7 or $1 \mathrm{mM}$ TEA, given the dose-response differences determined above. We found no significant difference in $\tau_{\text {finact }}$ or $\tau_{\text {sinact }}$ between OT and VP neurons, at either dose of TEA (Table 1). We also found no dose effect for either $\tau_{\text {finact }}$ or $\tau_{\text {sinact }}$ within either cell type. Even though these experiments were done in nominal extracellular $\mathrm{Ca}^{2+}$, to further rule out the possibility of TEA acting on $\mathrm{BK}$ channels activated from intracellular $\mathrm{Ca}^{2+}$, we tested the effect of $1 \mathrm{mM}$ TEA on 7 (4 VP, 3 OT) neurons recorded with $2 \mathrm{mM}$ BAPTA instead of $0.2 \mathrm{mM}$ EGTA in the pipette. The TEA-subtracted current with this stronger chelation showed amplitudes and time constants in both the fast (1.9-4 $\mathrm{nA} ; 17-96 \mathrm{~ms})$ and slow components (2.3-5.6 nA; 510-1,166 $\mathrm{ms}$ ) within the same range of those neurons recorded in 0.2 mM EGTA.

Consistent with the presence of Kv3-like channels, the TEA-subtracted tail currents $(0.7 \mathrm{mM})$ measured at $-50 \mathrm{mV}$, following a step to $+50 \mathrm{mV}$, always contained a substantial fast component of 1-2 ms and a slower component of variable length (5-25 ms) (Fig. 5). The $\tau$ of the rapidly deactivating portion of the tail current was $1.2 \pm 0.5 \mathrm{~ms}$ in VP neurons $(n=$ 7 ) and $1.4 \pm 0.4 \mathrm{~ms}$ in OT neurons $(n=7)$. The slower $\tau$ was $9.9 \pm 7.7 \mathrm{~ms}$ in VP neurons and $9.3 \pm 5 \mathrm{~ms}$ in OT neurons. Neither component was statistically different between cell types.

VERIFICATION OF KV3-LIKE PARAMETERS IN DISSOCIATED NEURONS. As discussed in METHODS, we verified our observations of Kv3-like currents in acutely dissociated neurons. The pro-

TABLE 1. Approximate inactivation time constants $(\tau)$ for the fast transient and slow components of TEA-sensitive current with a 2-s depolarizing pulse from -50 to $+50 \mathrm{mV}$

\begin{tabular}{lrrrr}
\hline \hline & \multicolumn{2}{c}{ VP Neurons } & & OT Neurons \\
\cline { 2 - 3 } & \multicolumn{1}{c}{$\tau$ fast, ms } & $\tau$ slow, ms & $\tau$ fast, ms & $\tau$ slow, ms \\
\hline 0.7 mM TEA & $11.3 \pm 2.6(n=6)$ & $1,538 \pm 978(n=6)$ & $24.6 \pm 12.9(n=7)$ & $1,049 \pm 409(n=7)$ \\
$1.0 \mathrm{mM}$ TEA & $9.6 \pm 2.3(n=9)$ & $1,896 \pm 552(n=9)$ & $17.4 \pm 5.5(n=7)$ & $1,367 \pm 544(n=7)$ \\
\hline
\end{tabular}

Values are means \pm SD. No statistical differences were found between OT and VP neurons, or between doses. 


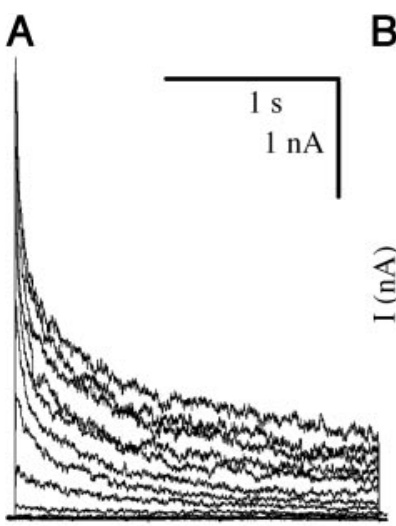

B

C
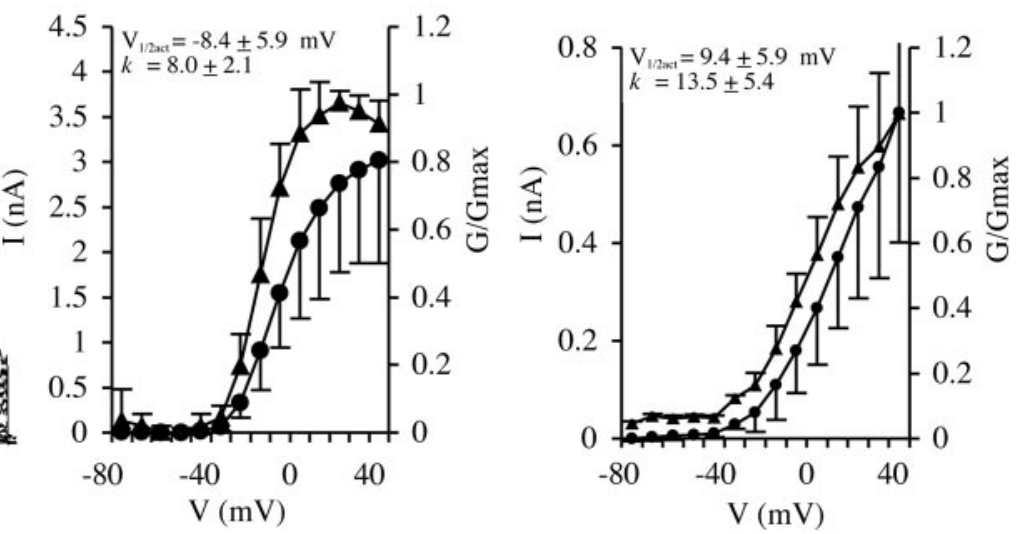

FIG. 6. Kv3-like currents in dissociated MNCs. A: digitally subtracted currents in a MCN illustrating TEA-sensitive (1 mM) component evoked from a holding potential of $-50 \mathrm{mV}$ (see protocol Fig. $1 \mathrm{Bb}$ ). B: peak transient (achieved by subtracting the persistent component before normalization). $C$ : persistent component of TEA-sensitive current amplitude $(I, \bullet)$ and normalized conductance $\left(\mathrm{G} / \mathrm{G}_{\max }, \mathbf{\Delta}\right)$ plotted against voltage $(V)(n=6)$.

cesses were truncated in these cells, resulting in improved space clamp. In addition, in most dissociated neurons the whole cell currents were much smaller, reducing errors attributed to series resistance. Because the TEA-subtracted persistent current was smaller in dissociated neurons, we examined 1 mM TEA-subtracted currents. Figure 6 shows subtracted currents in a dissociated neuron, and the voltage/current plots for 6 neurons. Both the peak transient and persistent portions activated at voltages depolarized to $-20 \mathrm{mV}$. Conductance plots for the peak TEA-sensitive current were well fit by a single Boltzmann function, with a mean slope factor $\mathrm{k}$ of $8 \pm$ 2.1 , and a mean $V_{1 / 2}$ of $-8.4 \pm 5.9 \mathrm{mV}$. The persistent current had a $\mathrm{k}$ value of $13.5 \pm 5.4$ and a $V_{1 / 2}$ value of $9.4 \pm 5.9 \mathrm{mV}$, but was not as well fit with a single Boltzmann function. At $+50 \mathrm{mV}$, the fast transient portion inactivated with a $\tau_{\text {finact }}$ of $15.4 \pm 6.7 \mathrm{~ms}$, the slow component with a $\tau_{\text {sinact }}$ of $1.0 \pm$ $0.25 \mathrm{~s}$, values similar to those recorded in slices at this dose. Over the range of +10 to $+50 \mathrm{mV}$, neither $\tau_{\text {finact }}$ nor $\tau_{\text {sinact }}$ showed a consistent voltage dependency (not shown). In general, the slope and half activation of the persistent current matched well to Kv3-like currents in expression systems, whereas for the transient current the $1 / 2$ activation is $10-20$ $\mathrm{mV}$ more hyperpolarized than Kv3.3/3.4-like currents (Coetzee et al. 1999; Fernandez et al. 2003; Rudy et al. 1999).

\section{High-threshold $K^{+}$currents in MNCs are not blocked by dendrotoxin (DTX)}

Although most Kv1 family subunits underlie persistent currents, in association with accessory $\beta$ subunits some Kv1 subtypes form a transient $\mathrm{K}^{+}$current that may be sensitive to low doses of TEA (Heinemann et al. 1996; Rhodes et al. 1997) and to DTX (e.g., Kv1.1, 1.2, and 1.6). We tested DTX at a concentration of $100 \mathrm{nM}(n=7)$ and found no significant effect on either the peak $(-1.1 \pm 8 \%)$ or the persistent component $(-6.4 \pm 7.9 \%$ ) (Fig. 7). Even a dose of $1 \mu \mathrm{M}$ failed to reduce the current $(n=2$; not shown). Thus it is unlikely that the high-voltage components studied here derive from DTX-sensitive, Kv1-like currents in the SON.

\section{BDS-I suppresses the high-threshold $K^{+}$current in MNCs}

Kv3.4 currents in homomeric expression systems are strongly inhibited by the sea anemone peptides BDS-I and -II, in the $\mathrm{nM}$ range (Diochot et al. 1998). In 7 MNCs tested in slices (including $2 \mathrm{VP}$ and 1 OT neuron), BDS-I (100 nM) reversibly blocked a small portion of the peak high-threshold current compared with controls (Fig. 8) $(12.9 \pm 9 \% ; P<0.03$; $n=7)$. A smaller portion of the persistent current also was blocked $(8.7 \pm 7.8 \% ; P<0.02)$.

\section{Role of Kv3-like currents in action potential repolarization and firing frequency}

To determine the functional contribution of Kv3-like currents in the SON, we examined the effects of TEA and BDS on action potentials (APs) in slices. To compare our results with the voltage-clamp experiments, $\mathrm{Ca}^{2+}$ was removed from the ACSF. Spike broadening in response to TEA was dose-dependent (Fig. 9). Whereas sigmoid plots were well fit to doses to $\leq 1 \mathrm{mM}$ for $1 / 2$ width, for base width these plots deviated at 1 $\mathrm{mM}$ in both VP and OT neurons. This was reminiscent of the dose-response curves for block of the persistent current (Fig. 4), where $1 \mathrm{mM}$ TEA begins to block an additional, slow current. Although there was little difference in the $1 / 2$ maximal dose for TEA between cell types, the amount of AP broaden-

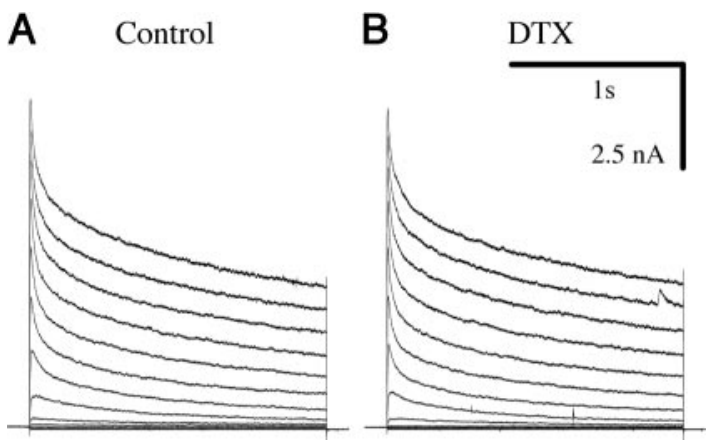

FIG. 7. Dendrotoxin (DTX) fails to affect the high-threshold outward current evoked from $-50 \mathrm{mV}$. A: control; $B$ : $100 \mathrm{nM}$ DTX (see voltage protocol in Fig. 1Bb). 

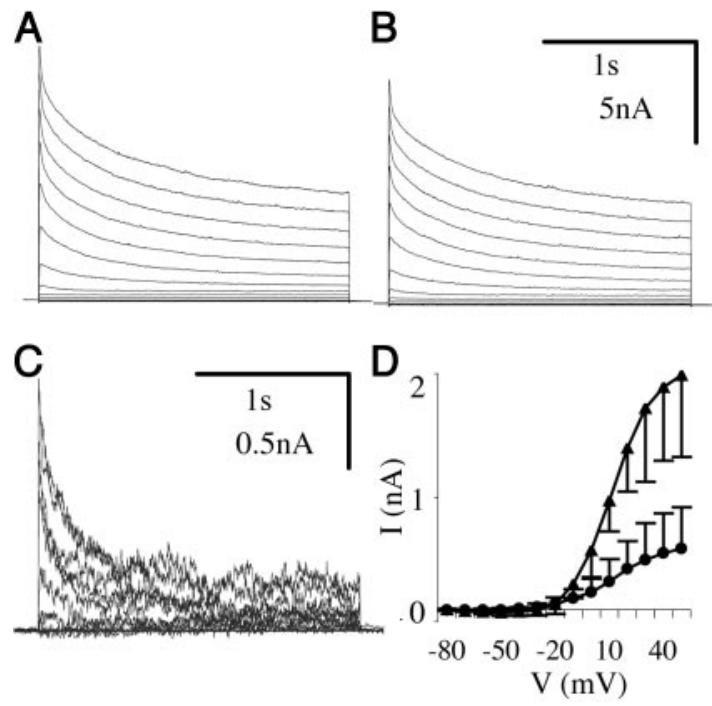

FIG. 8. High-threshold $\mathrm{K}^{+}$current is reduced by $100 \mathrm{nM}$ BDS-I in slices. $A$ : control current in a MNC; $B$ : current after $100 \mathrm{nM}$ BDS-I; $C$ : digitally subtracted traces illustrating $100 \mathrm{nM}$ BDS-I-sensitive current; $D$ : current $(I)$-voltage $(V)$ plots for BDS-I-sensitive peak transient current $(\mathbf{\Lambda})$ and persistent current $(\bullet)(n=7)$. Neurons were held at $-50 \mathrm{mV}$ and stepped for $2 \mathrm{~s}$ from -80 to $+50 \mathrm{mV}$, then to $-80 \mathrm{mV}$.

ing, induced by TEA at base width, was greater in VP neurons. Doses of $0.4(P<0.002), 0.6(P<0.0009)$, and $1 \mathrm{mM}(P<$ $0.003)$ TEA produced significantly greater broadening at the AP base in VP neurons. The difference between the 2 types at $1 / 2$ width was significant only for $1 \mathrm{mM}$ TEA $(P<0.006)$. TEA-sensitive currents, including Kv3 types, appear to have a greater role for AP repolarization in VP versus OT neurons. As a further control for the possibility that intracellular $\mathrm{Ca}^{2+}$ may allow some BK channel activity during spikes, we tested $1 \mathrm{mM}$ TEA with $2 \mathrm{mM}$ BAPTA in the pipette instead of $0.2 \mathrm{mM}$ EGTA. TEA still potently broadened spike $1 / 2$ half-width and base width in both cell types ( $n=10$ for each type) to degrees similar to those observed in $0.2 \mathrm{mM}$ EGTA (VP: $1 / 2$ width ratio $=194 \pm 24 \%$; base width ratio $=302 \pm 107 \%$; OT: $1 / 2$ width $167 \pm 10 \%$; base width ratio $=177 \pm 19 \% ; P<0.005$ for both cell types).

At a dose of $100 \mathrm{nM}$, BDS-I produced a small (10-13\%) but significant AP broadening at half-amplitude in OT $(P<0.04$; $n=5)$ and VP neurons $(P<0.03 ; n=7)$ (Fig. 9). The effects at base width were smaller (7-8\% increase) and not statistically significant for either cell type. No difference in the degree of broadening was found between OT and VP neurons. Whereas BDS-I had no effect in VP neurons on spike amplitude (control: $80.3 \pm 6.9$ vs. BDS: $81.4 \pm 8.1 \mathrm{mV}$ ) or rise time (control: $0.17 \pm 0.02$ vs. BDS-I: $0.18 \pm 0.03 \mathrm{~ms}$ ), in OT neurons each of these was slightly yet significantly altered. Amplitude was reduced $(76.3 \pm 12.5$ vs. $70 \pm 13 \mathrm{mV} ; P<$ 0.04 ) and rise time was slowed (control: $0.23 \pm 0.09$ vs. BDS-I: $0.27 \pm 0.12 \mathrm{~ms} ; P<0.04$ ) in OT neurons. Although the reason for this discrepancy between OT and VP neurons is unclear, it should be noted that BDS-I shares homology with other anemone $\mathrm{Na}^{+}$channel toxins and thus may act as a weak $\mathrm{Na}^{+}$channel blocker (Diochot et al. 1998). If this were the reason, then it would suggest some difference in OT and VP neurons in this regard.
To determine the impact of TEA-sensitive currents on firing rate, neurons were depolarized with a 60-pA, 500-ms pulse. Because of the deviation from a sigmoid at $1 \mathrm{mM}$ TEA in spike broadening as well as the suppression of a slower current (see above), neurons were tested at 0.6 and $1 \mathrm{mM}$ TEA, in both OT and VP neurons. As shown in Fig. 10, both 0.6 and $1 \mathrm{mM}$ TEA reduced the evoked firing frequency to a similar degree, in both OT and VP neurons. No differences were found between neuron types, or between the response at 0.6 and $1 \mathrm{mM}$ TEA. Interestingly, both neuron types showed a small degree of rate-dependent broadening during these evoked trains that was still present after TEA treatment. However, because TEA affected the evoked spike frequency, and spike broadening is known to be frequency dependent, we did not statistically compare rate-dependent broadening among these groups.

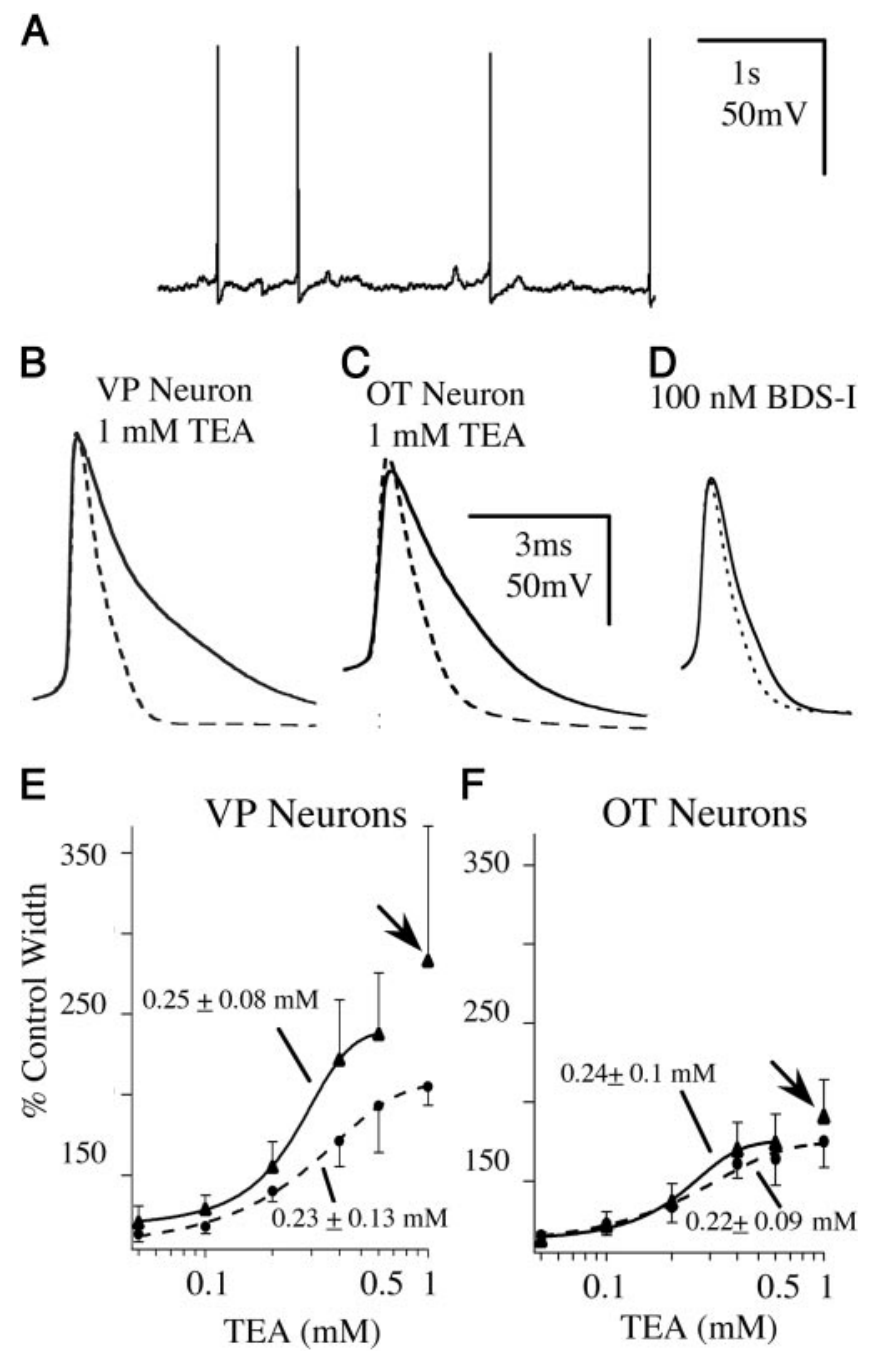

FIG. 9. Effect of TEA and BDS-I on spike width in slices. A: action potentials (APs) recorded in a MNC. $B-D$ : effect of $1.0 \mathrm{mM}$ TEA on AP broadening in VP neuron $(B)$ and $\mathrm{OT}$ neuron $(C)$, and example of $\mathrm{AP}$ broadening induced by BDS-I $(D)$. Control spikes are shown with dashed lines, drug effects with solid lines. $E$ : dose-response of AP broadening to TEA in VP neurons $(E)$ and OT neurons $(F)$. $(\bullet+$ dashed line, width at an AP halfamplitude; $\boldsymbol{\Lambda}+$ solid line, width at base). Values shown are the 1/2 maximal doses of TEA after fitting a single sigmoid function to the plots. Arrows show points at $1 \mathrm{mM}$ TEA that were not included in the fits for base width because they strongly reduced the goodness of fit. 
A Control $0.6 \mathrm{mM}$ TEA

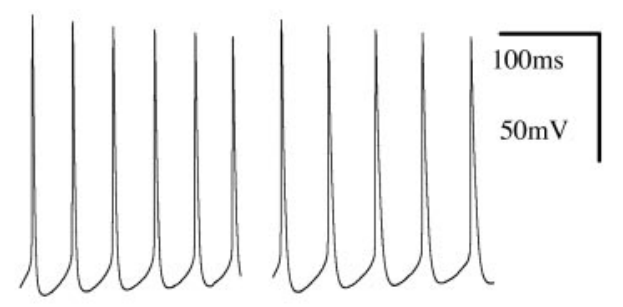

B

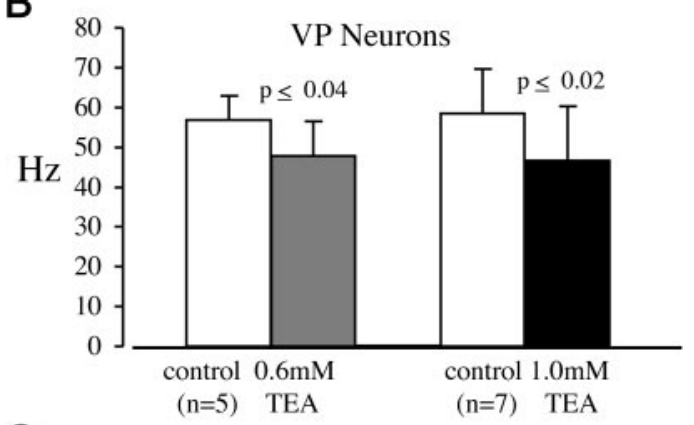

C

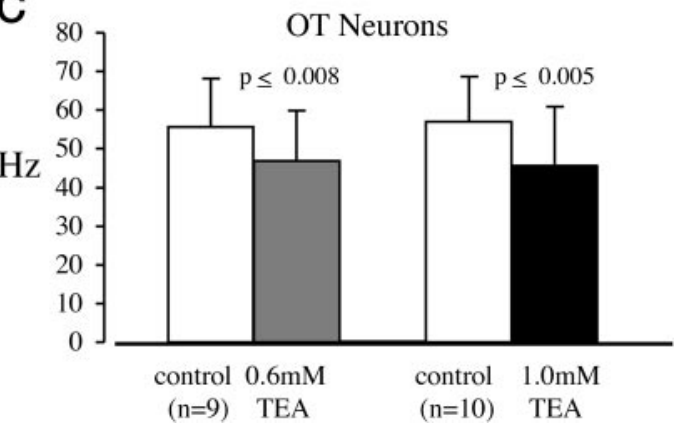

FIG. 10. TEA reduces evoked firing rates in MNCs. A: firing pattern in a VP neuron before (Control) and after $0.6 \mathrm{mM}$ TEA. Firing was evoked by injection of 60-pA, 500-ms current pulse. First $200 \mathrm{~ms}$ of each train is shown. $B$ and $C$ : mean evoked (60-pA, 500-ms) firing frequencies in VP neurons $(B)$ and OT neurons $(C)$ after 0.6 and $1 \mathrm{mM}$ TEA. Number of neurons tested is given in parentheses.

\section{Localization of Kv3-like immunoreactivity}

Specific immunoreactivity in the SON was observed with the antibody raised against the Kv3.1b subunit (Figs. 11-13). Although some of the strongest labeling was in VP processes, the somata were also clearly labeled. Labeled processes were similar in morphology and location to both the dendrites and the axons of SON neurons (Armstrong et al. 1982). Thus many thicker processes were found in the ventral dendritic lamina, and fine-beaded processes were observed dorsally and throughout the hypothalamo-neurohypophysial pathway, including the neural lobe (Fig. 12). This reactivity was strongly suppressed with absorption of the Kv3.1b peptide (Fig. 12). Antibodies against the $\mathrm{Kv} 3.4,3.2$, and 3.3 peptide did not result in detectable staining in the SON or the neurohypophysial tract. Double-labeling experiments revealed that the Kv3.1b immunoreactivity was associated more strongly with VP neurons (Fig. 13), but was weakly associated with OT neurons. Staining was also present in the MNCs within the PVN (not shown).

\section{I S C U S S I O N}

Based on voltage dependency, high sensitivity to TEA, sensitivity to BDS-I, insensitivity to dendrotoxin, fast deacti- vation kinetics, persistence in 0 extracellular $\mathrm{Ca}^{2+}$, and the localization of $3.1 \mathrm{~b}$ immunoreactivity, we infer the presence of Kv3-like currents in MNCs. Previous investigators of mRNA or protein distribution in whole rat brain failed to mention the SON or PVN as containing any of the Kv3-like channels, and indicated a low expression in hypothalamus in general (Perney et al. 1992; Weiser et al. 1994, 1995). However, the SON appears labeled in a low-power micrograph in Fig. $2 b$ of Weiser et al. (1995), using a Kv3.1b antibody generated against the identical, c-terminal amino acid sequence (residues 567-585) as the Alomone Labs antibody used herein. Weiser et al. (1995) commented on the numerous labeled axons in the hypothalamus, citing this as a possible reason for the absence of Kv3.1b mRNA in this region. Although we also observed many labeled hypothalamic axons, the labeling of SON dendrites and somata was unambiguous.

Many electrophysiological analyses of MNCs have revealed high voltage-activated, slowly inactivating $\mathrm{K}^{+}$currents (Cobbett et al. 1989; Hlubek and Cobbett 1997; Li and Ferguson 1996; Luther et al. 2000). However, with one exception (Hlubek and Cobbett 1997), there has been no evidence for Kv3-like activity among these currents. Hlubek and Cobbett (1997) reported an additional transient outward current that activated at much higher voltages than $I_{\mathrm{A}}$, and which was strongly modulated by external $\mathrm{Ca}^{2+}$. Except for the $\mathrm{Ca}^{2+}$ dependency, this current appears similar to the transient $\mathrm{K}^{+}$ current we studied. As for the $\mathrm{Ca}^{2+}$ dependency, Hlubek and Cobbett (1997) determined that the suppression of the guinea pig transient current with $\mathrm{Cd}^{2+}$ - or $\mathrm{Ca}^{2+}$-free media was not the result of a shift in voltage dependency. In the present study, the transient current was robust and present in all neurons recorded with negligible $\left[\mathrm{Ca}^{2+}\right]_{\mathrm{O}}$. Whether the $\mathrm{Ca}^{2+}$ dependency in guinea pig represents a real species difference from rat or is the result of other technical differences between this and the data of Hlubek and Cobbett (1997), remains to be determined. In addition, both the transient and persistence currents were still strongly affected by TEA after increasing $\mathrm{Ca}^{2+}$ buffering with $2 \mathrm{mM}$ BAPTA, suggesting little contribution of BK channels to the effects described herein.

\section{The transient, TEA-sensitive Kv3-like current}

Whereas the $1 / 2$ activation voltage of the transient $\mathrm{K}^{+}$ current in dissociated cells was $10-20 \mathrm{mV}$ hyperpolarized to most Kv3-type currents in expression systems, the threshold, inactivation kinetics, and sensitivity of this current to TEA strongly imply the presence of Kv3.3/3.4 subunits (Coetzee et al. 1999; Fernandez et al. 2003; Rudy et al. 1999). Unlike the persistent current (see following text), the inhibition of the transient current with TEA was well fit by a Hill plot up to a concentration of $1 \mathrm{mM}$, where about $40 \%$ of the peak current was blocked. We determined a small but consistent effect of a low $(100 \mathrm{nM})$ dose of BDS-I on the transient current, consistent with expression of the $\mathrm{Kv} 3.4$ subtype. The $\mathrm{IC}_{50}$ for the BDS-I block of Kv3.4 channels in expression systems is in the nM range (Abbott et al. 2001; Diochot et al. 1998), whereas the BDS-I sensitivity of natively expressed channels either can be similar (Chabbert et al. 2001) or in the low micromolar range (Abbott et al. 2001; Riazanski et al. 2001). Interestingly, coexpression of the Kv3.4 splice variant Kv3.4a with Kv3.1b type channels can produce a $\mathrm{K}^{+}$current profile much like what 

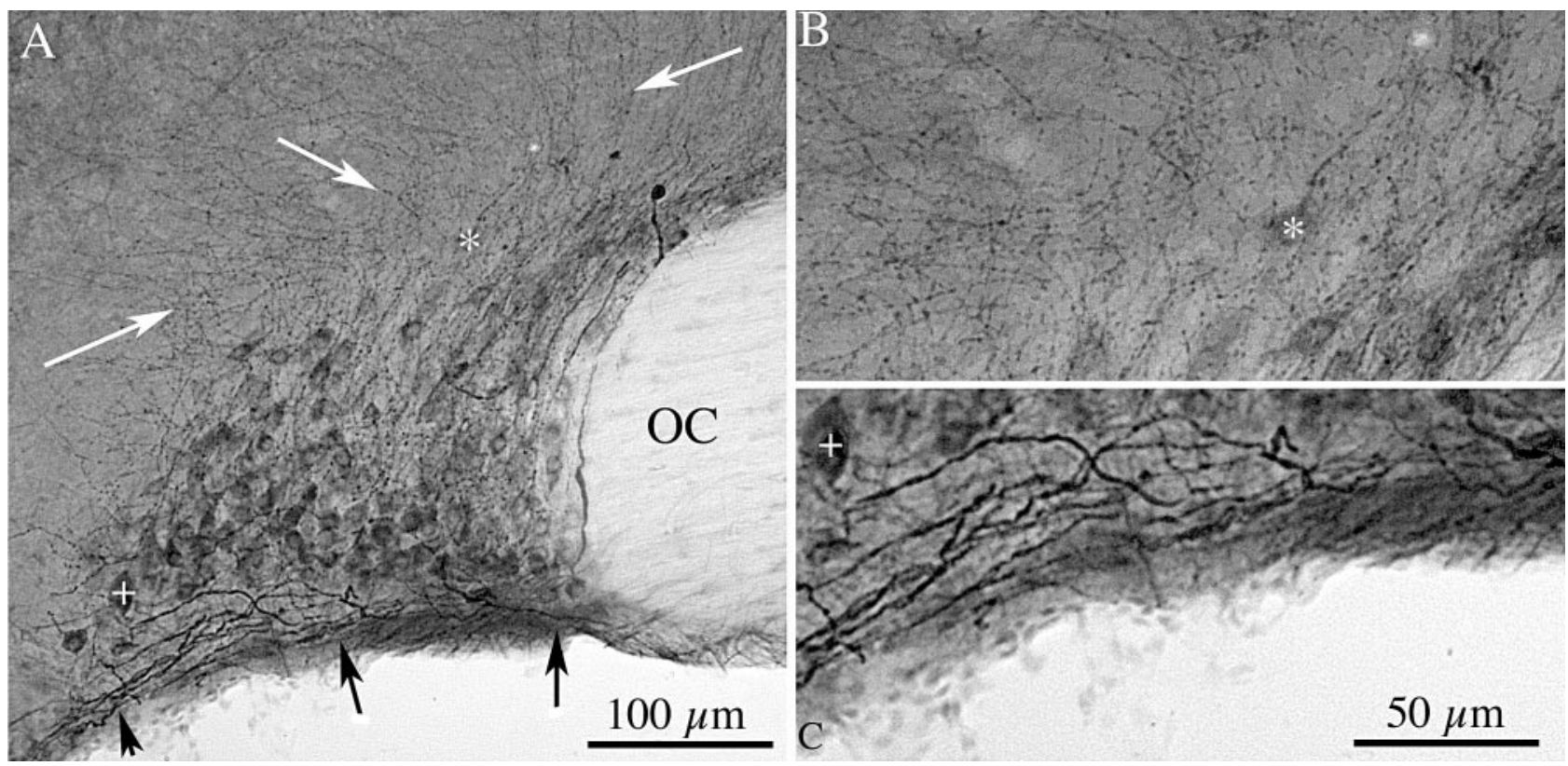

FIG. 11. Immunochemical localization of Kv3.1b immunoreactivity in the supraoptic neuron (SON). A: low-power photomicrograph of the rat SON in $75-\mu \mathrm{m}$ coronal section, ABC staining. This micrograph is a synthetic projection from an average of 10 optical sections, each $2 \mu \mathrm{m}$ apart (see METHODS). Note the staining of thick processes in the ventral dendritic lamina (black arrows) and that of fine-beaded processes dorsally (white arrows). In addition, numerous cells are reactive, particularly in the ventral part of the nucleus. Stained neurons that serve as references for $B$ are indicated by a white + and *. OC, optic chiasm. B: higher magnification of the dorsal region with lightly stained neurons and fine axonal-like processes. White * denotes a lightly stained cell in $A$. Scale as in $C$. C: higher magnification of the ventral dendritic lamina region, with thick stained processes. White + marks a darkly stained cell in $A$.

we observed here, both natively in globus pallidus neurons and after transfection in HEK cells (Baranauskas et al. 2003). The coassembly of these subunits in HEK cells shifted the voltage dependency of the Kv3.4 channels negatively, resembling the pallidal neurons that were also shown to have coassembling Kv3.4a and Kv3.1 mRNA. Unfortunately, we could not verify the presence of either Kv3.3- or Kv3.4-like subunits in the SON with immunochemistry. It is difficult to conclude much with negative immunochemical results, so further work will be necessary to verify the molecular configuration underlying this current. Indeed, a single Kv3.4 subunit in heterogenic Kv3 channel clusters can dramatically alter the Kv3 current profile and impart a transient component (Weiser et al. 1994). Thus a low expression may account for the lack of reactivity. In addition, the Kv3.3 antibody we used is specific to the Kv3.3a splice variant, so it might be possible that some Kv3.3b went undetected. It is also clear that activation, and steady-state inactivation voltages, may vary widely for Kv3.3/3.4 transient currents (e.g., Chabbert et al. 2001; Martina et al. 2003). Thus we exert caution in interpreting our data as a quantitative estimate of the relative proportion of transient-type current because it is possible that a portion of the current was inactivated at $-50 \mathrm{mV}$. The main point is that a high-threshold, transient current exists, and it fits a Kv3.3-3.4-type profile.

\section{The persistent TEA-sensitive Kv3-like current}

Delayed rectifier type $\mathrm{K}^{+}$currents have often been observed in MNCs (Cobbett et al. 1989; Hlubek and Cobbett 1997; Li and Ferguson 1996; Luther et al. 2000), but there has been little characterization of their voltage dependency and precise sensitivity to TEA. This is the first report to suggest that at least a portion of the slowly decaying component of a delayed rectifier current in the SON involves Kv3.1 channels, which activate at similar voltages and show slow inactivation kinetics and high TEA sensitivity in expression systems (Coetzee et al. 1999; Rudy et al. 1999). Whereas a range of inactivation time constants may be associated with Kv1 type subunits, these channels typically activate at lower voltages than reported here, and, like Kv2 subtypes, are relatively insensitive to TEA. Furthermore, several (i.e., Kv1.1, 1.2, and 1.6) are sensitive to DTX in the low nM range. The DTX effect on many Kv1 channel subtypes is reasonably selective and preferable to another blocker, 4-AP (Stansfeld et al. 1986; Wu and Barish $1992)$, which at even low concentrations $(\sim 100 \mu \mathrm{M})$ inhibits a number of Kv1, Kv2, and Kv3 family channels. In combination with the voltage dependency, the absence of even a small effect of $100 \mathrm{nM} \alpha$-DTX would argue against the strong presence of

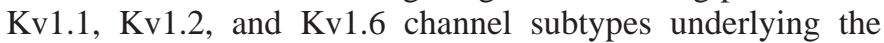
TEA-sensitive macroscopic current we examined. As mentioned above, the small sensitivity of the persistent current to BDS-I could suggest some heterogenic expression of Kv3.1/ 3.2 and Kv3.4 subtypes (Baranauskas et al. 2003).

Whereas low doses of TEA $(0.05-0.7 \mathrm{mM})$ suppressed the persistent current consistent with a single site of action, at 1 mM TEA a distinctly larger portion of this current was blocked. This was especially marked in VP neurons, where the amount of persistent current blocked jumped from about $20 \%$ at $0.7 \mathrm{mM}$ to about $75 \%$ at $1 \mathrm{mM}$. This would be consistent with additional high-threshold $\mathrm{K}^{+}$channel subtypes in MNCs. Based on this deviation, it might be assumed that non-Kv3-like currents account for much of the persistent current in MNCs. There are many possibilities for these additional currents, but 

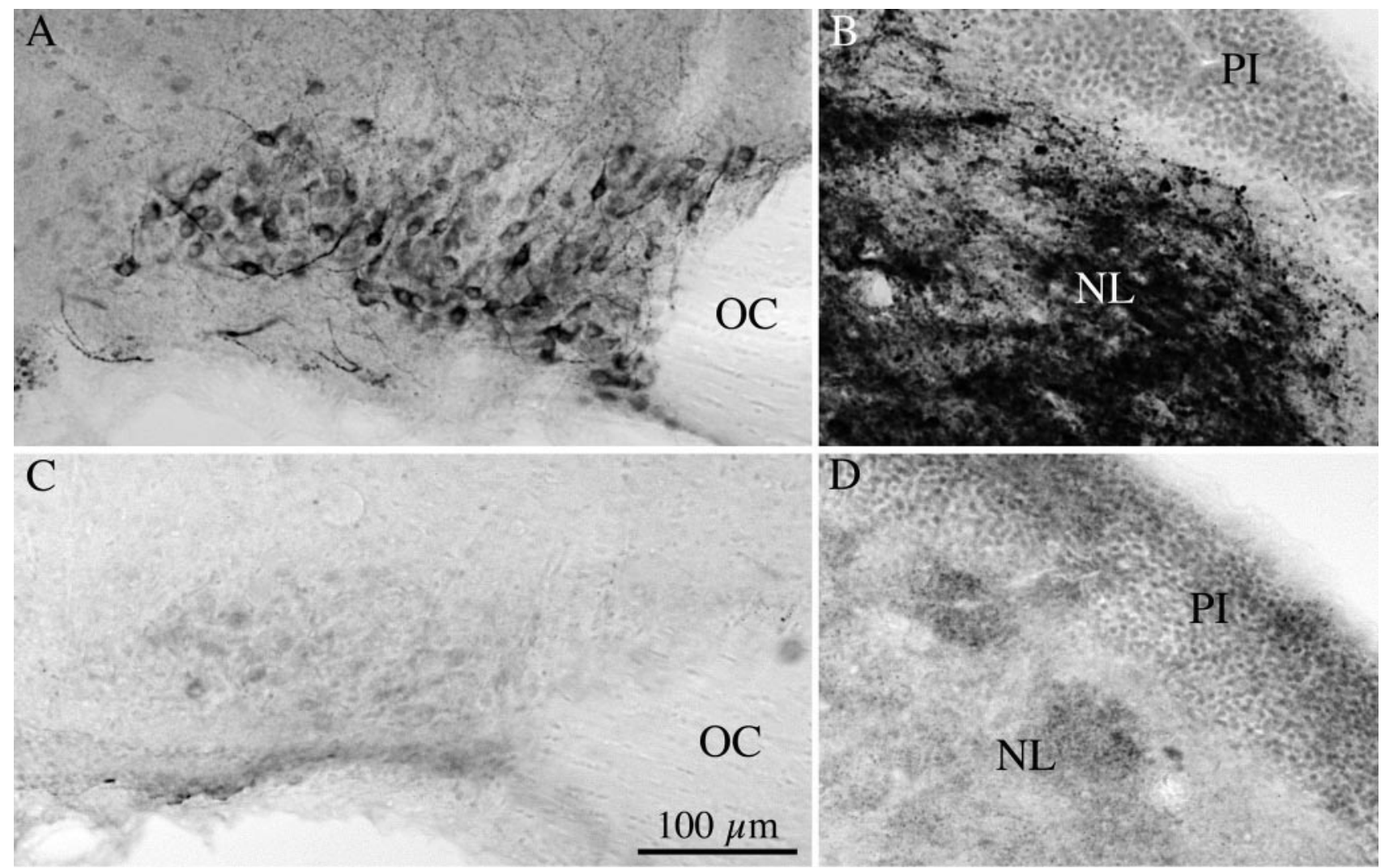

FIG. 12. Absorption of Kv3.1b peptide reduces immunoreactivity in the SON and in the neural lobe (NL). $A$ and $B$ : immunochemical localization of $\mathrm{Kv} 3.1 \mathrm{~b}$ in $40-\mu \mathrm{m}$ frozen sections through the SON $(A)$ and NL (B); OC, chiasm. $C$ and $D$ : co-incubation of Kv3.1b peptide $(1 \mu \mathrm{g} / \mu \mathrm{g}$ antibody) strongly reduces reactivity in adjacent sections of the SON $(C)$ and NL $(D)$. Note nonspecific staining in $D$ in the pars intermedia (PI) is still present after absorption.

Kv2 family tail currents natively expressed in GP neurons show an $\mathrm{IC}_{50}$ of about $0.8 \mathrm{mM}$ TEA (Baranauskas et al. 1999). Alternatively, it is striking that the expression of Kv3.1b immunoreactivity is much greater in VP than in OT neurons, despite a roughly similar inhibition of persistent current at the lower doses of TEA. Future studies need to examine more precisely the molecular configuration of $\mathrm{Kv}$ subunits (e.g., presence of splice variants), and relate these more precisely to activation, deactivation, and inactivation parameters in identified OT and VP neurons, under conditions with optimal space clamp and series resistance. As stated previously, the difficulty posed by coexpression of OT and VP mRNA offsets the advantages offered by dissociated cells to address these issues.

\section{Functional significance of Kv3 channels for AP repolarization and firing}

The presence of Kv3-like activity in neurons has previously been associated with large $\mathrm{K}^{+}$currents in fast spiking cells, such as cortical interneurons, or some brain stem auditory neurons (Rudy and McBain 2001). Whereas MNCs demonstrate both repetitive and burst firing under different conditions, the maximal firing rates achieved under most physiological challenges in vivo are typically $10-20 \mathrm{~Hz}$ (Poulain and Wakerley 1982; Poulain et al. 1988). The exception would be the brief (3-4 s) and periodic (10-20 min) OT cell bursts that occur during lactation, and can reach a frequency of $30-80 \mathrm{~Hz}$ (Richard et al. 1988). In either case, the maximal firing rates achieved are strongly related to the maximal facilitation of hormone release from terminals in the neural lobe (Bicknell 1988). In vitro, both cell types are capable of firing at rates from 50 to $100 \mathrm{~Hz}$ for only brief periods $(<1 \mathrm{~s})$, when under strong intracellular depolarization (Stern and Armstrong 1996; Teruyama and Armstrong 2002). Sustained firing rates in both OT and VP neurons types are largely limited by prominent calcium-dependent afterhyperpolarizing potentials that produce spike frequency adaptation (Armstrong et al. 1994; Bourque and Brown 1987; Greffrath et al. 1998), and these channels are diminished in fast-spiking neurons (Erisir et al. 1999). Thus it is interesting that, similar to their role in fast-spiking neurons (Rudy and McBain 2001), inhibition of the Kv3-like channels with low doses of TEA suppressed depolarization-induced firing rates in MNCs. Because calciumdependent afterhyperpolarizations in MNCs typically require spike trains for strong activation and the effects of TEA are present after the first spike (Fig. 10), Kv3-like channels would serve to maximize the initial firing rate response in MNCs.

We found a strong, submillimolar TEA sensitivity to spike width in both OT and VP neurons with a $1 / 2$ maximal dose (for single fits) similar to that observed for suppressing the Kv3like currents in voltage clamp, suggesting Kv3-like currents participate in spike repolarization in MNCs. Furthermore, at a low dose $(100 \mathrm{nM})$ the more specific Kv3.4 channel blocker, BDS-I, also broadened spikes at $1 / 2$ width. The latter result may suggest a more specific role for Kv3.4 activity in spike decay rather than the afterhyperpolarization. Together, these 

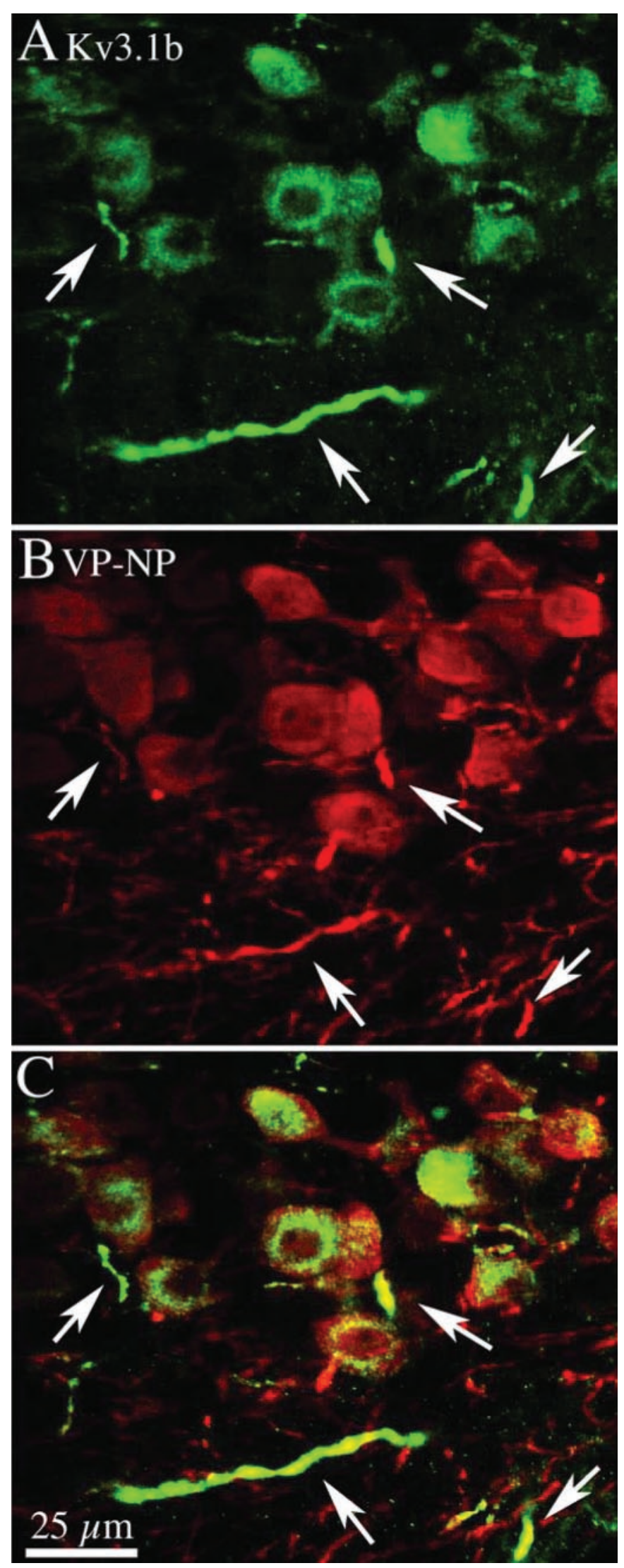

data support that Kv3.1- and Kv3.4-like currents participate in $\mathrm{AP}$ repolarization in MNCs. At this point, it is unknown whether these subunits exist as homomeric or heteromeric channels in SON neurons. In general, Kv3 subtypes are rapidly activating, rapidly deactivating, and have a high threshold, giving rise to questions as to how they can make a significant contribution to APs that remain depolarized for only brief periods. However, given sufficient channel density, these features ensure that Kv3 subtypes primarily affect the repolarization phase of APs (Rudy and McBain 2001). In addition, recent studies show that heteromeric expression of Kv3.4 and Kv3.1 subunits allows a stronger contribution of Kv3 types to AP repolarization by shifting the $1 / 2$ activation voltage negatively (Baranauskas et al. 2003), much like what we observed for the peak TEA-sensitive current in dissociated cells. Interestingly, much like the difference in block at $1 \mathrm{mM}$ TEA of the fast versus the persistent $\mathrm{K}^{+}$current, the dose response for TEA broadening of the base, but not the half-width, of the AP deviated at $1 \mathrm{mM}$. Again, this may indicate the participation of other $\mathrm{Kv}$ families in AP repolarization. Their stronger contribution to width near the end of spike repolarization is reminiscent of the inferred contribution of BK-type $\mathrm{Ca}^{2+}$ channels to APs in these neurons after iberiotoxin application, which affects spike width only at the base (Dopico et al. 1999; Roper et al. 2003). The similar actions of TEA on both $1 / 2$ and base spike width with $2 \mathrm{mM}$ BAPTA versus $0.2 \mathrm{mM}$ EGTA further suggests little contribution of $\mathrm{BK}$ channel activation from spikes when omitting $\mathrm{Ca}^{2+}$ from the ACSF. It is thus likely that a $\mathrm{Kv}$ channel of different activation and/or inactivation kinetics from $\mathrm{Kv} 3$ types or BK channel mediated currents also makes a contribution to spike repolarization in MNCs.

The differential effects of TEA on VP and OT neuron APs could relate to the stronger expression of Kv3.1b immunoreactivity in VP neurons. Whereas the similar 1/2 maximal dose for TEA in the 2 cell types indicates participation of Kv3 channels in both cell types, the stronger effect of TEA on the AP base width in VP neurons, even at submillimolar doses, suggests Kv3 channels, probably of the Kv3.1b subtype, have a greater importance to VP neurons. In this regard it is worth noting that not only are many of the parameters of activation and inactivation of Kv3-like channels unknown between the 2 cell types, we did not estimate current density attributed to the probable errors contributed by dendritic components to whole cell capacitance measurements. Thus although we observed qualitatively and even quantitatively similar current profiles in slices for both cell types, for the reasons discussed above regarding space clamp and series resistance, the currents could be quantitatively different. However, examining the effects on spike width does not suffer from these same pitfalls, and presumably the differential ability of TEA to affect spike width reflects a difference among the currents underlying spikes in the 2 cell types.

FIG. 13. Co-localization of Kv3.1b and VP-NP immunoreactivity. A: confocal image of Kv3.1b immunoreactivity labeled with FITC-conjugated secondary antibody (1 $\mu \mathrm{m}$ optical section). Stained neurons and thick processes (arrows) are visible. B: VP-NP immunoreactivity (PS 41 antibody) labeled with Texas Red-conjugated secondary in the same section and image plane as in $A$. $C$ : images in $A$ and $B$ merged. Overlap of the green FITC and the Texas Red-labeled elements indicated by yellow. Note the extensive overlap in some thick processes (arrows) as well as many neurons. 
Both VP and OT neurons undergo a similar degree of spike broadening during repetitive firing (Stern and Armstrong 1996; Teruyama and Armstrong 2002). This frequency-dependent broadening is strongly calcium-dependent (Bourque and Renaud 1985; Hlubek and Cobbett 2000) and may be important for facilitating the calcium influx into somata and dendrites that is necessary for the local, calcium-dependent release of VP, OT, and co-localized peptides like dynorphin (Ludwig 1998). Previous studies have shown that frequency-dependent broadening is controlled by a rate-dependent inactivation of $\mathrm{K}^{+}$ currents, including $I_{\mathrm{A}}$-type currents, as well as an increase in $\mathrm{Ca}^{2+}$ influx in MNCs (Hlubek and Cobbett 2000; Kirkpatrick and Bourque 1991; O'Regan and Cobbett 1993). In cortical pyramidal neurons, increases in spike width similar to those seen during rate-dependent broadening in MNCs (approximately doubling the width) provide a proportional increase in calcium entry (Stewart and Foehring 2001). Frequency-dependent spike broadening is blocked by $1 \mathrm{mM} 4-\mathrm{AP}$, but is present, albeit with much altered time course, during a large dose (5 $\mathrm{mM}$ ) of TEA (Hlubek and Cobbett 2000). Given the importance of $I_{\mathrm{A}}$ to activity-dependent broadening and its stronger association with VP neurons (Fisher et al. 1998; Stern and Armstrong 1997), it is somewhat surprising that no differences have been reported in broadening between the 2 neuron types in normal animals. In pregnancy and lactation, however, frequency-dependent broadening is more pronounced in OT than in VP neurons (Stern and Armstrong 1996; Teruyama and Armstrong 2002). The currents responsible for this change during reproductive state are unknown, although if changes in $I_{\mathrm{A}}$ and/or calcium currents underlie this increase, the diminished role of Kv3-like currents in OT neurons may be favorable to this enhanced broadening. Similarly, if high-voltage calcium channel density were higher in VP neurons, the increased presence of Kv3-like channels would allow considerable restraint of rate-dependent broadening, and thus spike frequency fidelity, without sacrificing the calcium influx necessary to activate the several calcium-dependent potentials that underscore burst activity in these neurons (Roper et al. 2003).

\section{A C K N O W L E D G MENTS}

The authors thank Dr. Bob Foehring for comments on a previous version of the manuscript, and T. Hobson for technical assistance. We thank Drs. S. Diochot and M. Lazdunski (Centre National de la Recherche Scientifique, Valbonne, France) for the gift of BDS-I, Dr. Hal Gainer (National Institutes of Health) for monoclonal antibodies to oxytocin- (PS 36) and vasopressinneurophysin (PS 41), and Dr. Alan Robinson for the polyclonal antiserum to vasopressin-neurophysin. The software for deblurring digital micrographs was provided by Dr. Mel Park, Dept. of Anatomy and Neurobiology, UT, Memphis.

\section{G R A N T S}

This research was supported by National Institutes of Health Grants NS-23941 and HD-41002 to W. E. Armstrong.

\section{REFERENCES}

Abbott GW, Butler MH, Bendahhou S, Dalakas MC, Ptacek LJ, and Goldstein SA. MiRP2 forms potassium channels in skeletal muscle with Kv3.4 and is associated with periodic paralysis. Cell 104: 217-231, 2001.

Agard DA, Hiraoka Y, Shaw P, and Sedat JW. Fluorescence microscopy in three dimensions. Methods Cell Biol 30: 353-377, 1989.

Armstrong WE, Smith BN, and Tian M. Electrophysiological characteristics of immunochemically identified rat oxytocin and vasopressin neurones in vitro. J Physiol 475: 115-128, 1994.

Armstrong WE and Teruyama R. Localization of Kv3.1b-like immunoreactivity in supraoptic neurons. Soc Neurosci Abstr 27: 178.8, 2001.
Baranauskas G, Tkatch T, Nagata K, Yeh JZ, and Surmeier DJ. Kv3.4 subunits enhance the repolarizing efficiency of Kv3.1 channels in fastspiking neurons. Nat Neurosci 6: 258-266, 2003.

Baranauskas G, Tkatch T, and Surmeier DJ. Delayed rectifier currents in rat globus pallidus neurons are attributable to $\mathrm{Kv} 2.1$ and $\mathrm{Kv} 3.1 / 3.2 \mathrm{~K}(+)$ channels. J Neurosci 19: 6394-6404, 1999.

Beck EJ, Sorensen RG, Slater SJ, and Covarrubias M. Interactions between multiple phosphorylation sites in the inactivation particle of a $\mathrm{K}^{+}$channel. Insights into the molecular mechanism of protein kinase $\mathrm{C}$ action. $J$ Gen Physiol 112: 71-84, 1998.

Bicknell R. Downstream consequences of bursting activity in oxytocin neurones. In: Pulsatility in Neuroendocrine Systems, edited by Leng G. Boca Raton, FL: CRC Press, 1988, p. 62-74.

Bourque $\mathbf{C}$ and Brown DA. Apamin and d-tubocurarine block the afterhyperpolarization of rat supraoptic neurosecretory neurons. Neurosci Lett 82: 185-190, 1987.

Bourque CW. Transient calcium-dependent potassium current in magnocellular neurosecretory cells of the rat supraoptic nucleus. J Physiol 397: 331-347, 1988.

Bourque CW and Renaud LP. Activity dependence of action potential duration in rat supraoptic neurosecretory neurones recorded in vitro. J Physiol 363: 429-439, 1985.

Chabbert C, Chambard JM, Sans A, and Desmadryl G. Three types of depolarization-activated potassium currents in acutely isolated mouse vestibular neurons. J Neurophysiol 85: 1017-1026, 2001.

Chow A, Erisir A, Farb C, Nadal MS, Ozaita A, Lau D, Welker E, and Rudy B. K(+) channel expression distinguishes subpopulations of parvalbumin- and somatostatin-containing neocortical interneurons. J Neurosci 19: 9332-9345, 1999.

Cobbett P, Legendre P, and Mason WT. Characterization of three types of potassium current in cultured neurones of rat supraoptic nucleus area. J Physiol 410: 443-462, 1989.

Coetzee WA, Amarillo Y, Chiu J, Chow A, Lau D, McCormack T, Moreno H, Nadal MS, Ozaita A, Pountney D, Saganich M, Vega-Saenz de Miera E, and Rudy B. Molecular diversity of $\mathrm{K}^{+}$channels. Ann NY Acad Sci 868: 233-285, 1999.

Diochot S, Schweitz H, Beress L, and Lazdunski M. Sea anemone peptides with a specific blocking activity against the fast inactivating potassium channel Kv3.4. J Biol Chem 273: 6744-6749, 1998.

Dopico AM, Widmer H, Wang G, Lemos JR, and Treistman SN. Rat supraoptic magnocellular neurones show distinct large conductance, $\mathrm{Ca}^{2+}$. activated $\mathrm{K}^{+}$channel subtypes in cell bodies versus nerve endings. J Physiol 519: 101-114, 1999 .

Erisir A, Lau D, Rudy B, and Leonard CS. Function of specific $\mathrm{K}(+)$ channels in sustained high-frequency firing of fast-spiking neocortical interneurons. J Neurophysiol 82: 2476-2489, 1999.

Fernandez FR, Morales E, Rashid AJ, Dunn RJ, and Turner R. Inactivation of Kv3.3 potassium channels in heterologous expression systems. J Biol Chem 278: 40890-40898, 2003.

Fisher TE, Voisin DL, and Bourque CW. Density of transient $\mathrm{K}^{+}$current influences excitability in acutely isolated vasopressin and oxytocin neurones of rat hypothalamus. J Physiol 511: 423-432, 1998.

Greffrath W, Martin E, Reuss S, and Boehmer G. Components of afterhyperpolarization in magnocellular neurones of the rat supraoptic nucleus in vitro. J Physiol 513: 493-506, 1998.

Hamill OP, Marty A, Neher E, Sakmann B, and Sigworth FJ. Improved patch-clamp techniques for high-resolution current recording from cells and cell-free membrane patches. Pflügers Arch 391: 85-100, 1981.

Heinemann SH, Rettig J, Graack HR, and Pongs O. Functional characterization of Kv channel beta-subunits from rat brain. $J$ Physiol 493: 625-633, 1996.

Hernandez-Pineda R, Chow A, Amarillo Y, Moreno H, Saganich M, Vega-Saenz de Miera EC, Hernandez-Cruz A, and Rudy B. Kv3.1Kv3.2 channels underlie a high-voltage-activating component of the delayed rectifier $\mathrm{K}^{+}$current in projecting neurons from the globus pallidus. $\mathrm{J} \mathrm{Neu}$ rophysiol 82: 1512-1528, 1999.

Hlubek MD and Cobbett P. Outward potassium currents of supraoptic magnocellular neurosecretory cells isolated from the adult guinea pig. J Physiol 502: 61-74, 1997.

Hlubek MD and Cobbett P. Differential effects of $\mathrm{K}(+)$ channel blockers on frequency-dependent action potential broadening in supraoptic neurons. Brain Res Bull 53: 203-209, 2000. 
Hoshi T, Zagotta WN, and Aldrich RW. Biophysical and molecular mechanisms of Shaker potassium channel inactivation. Science 250: 533-538, 1990.

Kirkpatrick K and Bourque CW. Dual role for calcium in the control of spike duration in rat supraoptic neuroendocrine cells. Neurosci Lett 133: 271-274, 1991.

Kirkpatrick K and Bourque CW. Activity dependence and functional role of the apamin-sensitive $\mathrm{K}^{+}$current in rat supraoptic neurones in vitro. J Physiol 494: 389-398, 1996.

Li $\mathbf{Z}$ and Ferguson AV. Electrophysiological properties of paraventricular magnocellular neurons in rat brain slices: modulation of IA by angiotensin II. Neuroscience 71: 133-145, 1996.

Ludwig M. Dendritic release of vasopressin and oxytocin. J Neuroendocrinol 10: 881-895, 1998.

Luther JA, Halmos KC, and Tasker JG. A slow transient potassium current expressed in a subset of neurosecretory neurons of the hypothalamic paraventricular nucleus. J Neurophysiol 84: 1814-1825, 2000.

MacKinnon R. Determination of the subunit stoichiometry of a voltageactivated potassium channel. Nature 350: 232-235, 1991.

Martina M, Schultz JH, Ehmke H, Monyer H, and Jonas P. Functional and molecular differences between voltage-gated $\mathrm{K}^{+}$channels of fast-spiking interneurons and pyramidal neurons of rat hippocampus. J Neurosci 18: 8111-8125, 1998

Martina M, Yao GL, and Bean BP. Properties and functional role of voltage-dependent potassium channels in dendrites of rat cerebellar Purkinje neurons. J Neurosci 23: 5698-5707, 2003.

Nagatomo T, Inenaga K, and Yamashita H. Transient outward current in adult rat supraoptic neurones with slice patch-clamp technique: inhibition by angiotensin II. J Physiol 485: 87-96, 1995.

Neher E. Correction for liquid junction potentials in patch clamp experiments. Methods Enzymol 207: 123-131, 1992.

Oliet SH and Bourque CW. Properties of supraoptic magnocellular neurones isolated from the adult rat. J Physiol 455: 291-306, 1992.

O'Regan MH and Cobbett P. Somatic currents contribute to frequencydependent spike-broadening in supraoptic neuroendocrine cells. Neurosci Lett 161: 169-173, 1993.

Perney TM, Marshall J, Martin KA, Hockfield S, and Kaczmarek LK. Expression of the mRNAs for the Kv3.1 potassium channel gene in the adult and developing rat brain. J Neurophysiol 68: 756-766, 1992

Poulain DA, Brown D, and Wakerley, JB. Statistical analysis of patterns of electrical activity in vasopressin and oxytocin-secreting neurones. In: $\mathrm{Pul}$ satility in Neuroendocrine Systems, edited by Leng G. Boca Raton, FL: CRC Press, 1988, p. 120-154.

Poulain DA and Wakerley JB. Electrophysiology of hypothalamic magnocellular neurones secreting oxytocin and vasopressin. Neuroscience 7: 773808, 1982.

Rhodes KJ, Strassle BW, Monaghan MM, Bekele-Arcuri Z, Matos MF, and Trimmer JS. Association and colocalization of the Kvbeta1 and Kvbeta2 beta-subunits with Kv1 alpha-subunits in mammalian brain $\mathrm{K}^{+}$ channel complexes. J Neurosci 17: 8246-8258, 1997.

Riazanski V, Becker A, Chen J, Sochivko D, Lie A, Wiestler OD, Elger CE, and Beck H. Functional and molecular analysis of transient voltagedependent $\mathrm{K}^{+}$currents in rat hippocampal granule cells. J Physiol 537: 391-406, 2001.

Richard P, Moos F, and Freund-Mercier M-J. Bursting activity in oxytocin cells. In: Pulsatility in Neuroendocrine Systems, edited by Leng G. Boca Raton, FL: CRC Press, 1988, p. 75-97.
Roper P, Callaway J, Shevchenko T, Teruyama R, and Armstrong W. AHP's, HAP's and DAP's: how potassium currents regulate the excitability of rat supraoptic neurones. J Comput Neurosci 15: 367-389, 2003.

Rudy B, Chow A, Lau D, Amarillo Y, Ozaita A, Saganich M, Moreno H, Nadal MS, Hernandez-Pineda R, Hernandez-Cruz A, Erisir A, Leonard C, and Vega-Saenz de Miera E. Contributions of Kv3 channels to neuronal excitability. Ann NY Acad Sci 868: 304-343, 1999.

Rudy B and McBain CJ. Kv3 channels: voltage-gated $\mathrm{K}^{+}$channels designed for high-frequency repetitive firing. Trends Neurosci 24: 517-526, 2001.

Shevchenko TI and Armstrong WE. High threshold, TEA-sensitive potassium currents and their role in spike repolarization in supraoptic neurons. Soc Neurosci Abstr 27: 178.7, 2001.

Stansfeld CE, Marsh SJ, Halliwell JV, and Brown DA. 4-Aminopyridine and dendrotoxin induce repetitive firing in rat visceral sensory neurones by blocking a slowly inactivating outward current. Neurosci Lett 64: 299-304, 1986.

Stern JE and Armstrong WE. Changes in the electrical properties of supraoptic nucleus oxytocin and vasopressin neurons during lactation. J Neurosci 16: 4861-4871, 1996.

Stern JE and Armstrong WE. Sustained outward rectification of oxytocinergic neurones in the rat supraoptic nucleus: ionic dependence and pharmacology. J Physiol 500: 497-508, 1997.

Stern JE, Galarreta M, Foehring RC, Hestrin S, and Armstrong WE. Differences in the properties of ionotropic glutamate synaptic currents in oxytocin and vasopressin neuroendocrine neurons. J Neurosci 19: $3367-$ 3375, 1999.

Stern JE, Hestrin S, and Armstrong WE. Enhanced neurotransmitter release at glutamatergic synapses on oxytocin neurones during lactation in the rat. J Physiol 526: 109-114, 2000.

Stewart AE and Foehring RC. Effects of spike parameters and neuromodulators on action potential waveform-induced calcium entry into pyramidal neurons. J Neurophysiol 85: 1412-1423, 2001.

Surmeier DJ, Wilson CJ, and Eberwine J. Patch-clamp techniques for studying potassium currents in mammalian brain neurons. Methods Neurosci 19: 39-67, 1994.

Teruyama R and Armstrong WE. Changes in the active membrane properties of rat supraoptic neurones during pregnancy and lactation. J Neuroendocrinol 14: 933-944, 2002.

Wang LY, Gan L, Forsythe ID, and Kaczmarek LK. Contribution of the Kv3.1 potassium channel to high-frequency firing in mouse auditory neurones. J Physiol 509: 183-194, 1998.

Weiser M, Bueno E, Sekirnjak C, Martone ME, Baker H, Hillman D, Chen S, Thornhill W, Ellisman M, and Rudy B. The potassium channel subunit KV3.1b is localized to somatic and axonal membranes of specific populations of CNS neurons. J Neurosci 15: 4298-4314, 1995.

Weiser M, Vega-Saenz de Miera E, Kentros C, Moreno H, Franzen L, Hillman D, Baker H, and Rudy B. Differential expression of Shaw-related $\mathrm{K}^{+}$channels in the rat central nervous system. J Neurosci 14: 949-972, 1994

Wu RL and Barish ME. Two pharmacologically and kinetically distinct transient potassium currents in cultured embryonic mouse hippocampal neurons. J Neurosci 12: 2235-2246, 1992.

Xi D, Kusano K, and Gainer H. Quantitative analysis of oxytocin and vasopressin messenger ribonucleic acids in single magnocellular neurons isolated from supraoptic nucleus of rat hypothalamus. Endocrinology 140: 4677-4682, 1999. 